\title{
Processing emotional pictures and words: Effects of valence and arousal
}

\author{
ELIZABETH A. KENSINGER and DANIEL L. SCHACTER \\ Boston College, Chestnut Hill, Massachusetts \\ and Athinoula A. Martinos Center for Biomedical Imaging, Charlestown, Massachusetts
}

\begin{abstract}
There is considerable debate regarding the extent to which limbic regions respond differentially to items with different valences (positive or negative) or to different stimulus types (pictures or words). In the present event-related fMRI study, 21 participants viewed words and pictures that were neutral, negative, or positive. Negative and positive items were equated on arousal. The participants rated each item for whether it depicted or described something animate or inanimate or something common or uncommon. For both pictures and words, the amygdala, dorsomedial prefrontal cortex (PFC), and ventromedial PFC responded equally to all high-arousal items, regardless of valence. Laterality effects in the amygdala were based on the stimulus type (word = left, picture = bilateral). Valence effects were most apparent when the individuals processed pictures, and the results revealed a lateral/medial distinction within the PFC: The lateral PFC responded differentially to negative items, whereas the medial PFC was more engaged during the processing of positive pictures.
\end{abstract}

In our daily lives, we experience many events that trigger an emotional response: We receive a compliment, witness a car crash, or watch children playing in a park. One widely accepted framework used to classify these diverse emotional experiences describes emotion in two orthogonal dimensions: Valence is a continuum specifying how negative or positive an event is, whereas arousal refers to the intensity of an event, ranging from very calming to highly exciting or agitating (e.g., Lang, Greenwald, Bradley, \& Hamm, 1993; Mehrabian \& Russell, 1974; Russell, 1980). There has been much interest in understanding how these different dimensions influence the neural processes recruited during the processing of an emotional event, with particular emphasis on examining how processing in the amygdala and the prefrontal cortex (PFC) is affected by stimulus valence and arousal.

The amygdala often responds preferentially to fear-evoking stimuli, in comparison with stimuli evoking other types of emotions (e.g., happiness, disgust, or anger; Irwin et al., 1996; Morris et al., 1996; Phillips et al., 1997; Whalen et al., 1998; Whalen et al., 2001), and patients with damage to the amygdala often are disproportionately impaired at recognizing or expressing fear (Adolphs, Tranel, Damasio, \& Damasio, 1995; Broks et al., 1998; Scott et al., 1997). These findings initially had been interpreted as evidence that the amygdala plays a specific role in the processing of fear-related information, in comparison with other types of information (see Baas, Aleman, \& Kahn, 2004; David-

Correspondence concerning this article should be addressed to E. A. Kensinger, Department of Psychology, Boston College, McGuinn Hall 510, 140 Commonwealth Ave., Chestnut Hill, MA 02467 (e-mail: elizabeth .kensinger@bc.edu). son \& Irwin, 1999). In most of the studies demonstrating this preferential amygdala response, however, the fear-related stimuli were more arousing than the other types of stimuli. Therefore, a viable alternative interpretation is that amygdala activity is linked to the arousal of stimuli. In support of this interpretation, recent studies have demonstrated that the amygdala responds to a range of higharousal emotions (e.g., surprise or happiness; Breiter et al., 1996; Kim, Somerville, Johnstone, Alexander, \& Whalen, 2003; Whalen et al., 2001). In fact, nearly all studies that have examined amygdala activity to positive and negative stimuli matched in arousal have found that the amygdala responds to both types of stimuli (Garavan, Pendergrass, Ross, Stein, \& Risinger, 2001; Hamann, Ely, Grafton, \& Kilts, 1999; Hamann, Ely, Hoffman, \& Kilts, 2002; Hamann \& Mao, 2002). This finding has been replicated using pictorial stimuli (Anders, Lotze, Erb, Grodd, \& Girbaumer, 2004; Garavan et al., 2001; Hamann et al., 2002), olfactory stimuli (Anderson et al., 2003; Royet et al., 2000), and gustatory stimuli (Small et al., 2003). Across these modalities, amygdala activity has been found to relate to the intensity, or arousal, of the stimuli, irrespective of valence (but see Kim et al., 2003, for evidence that whereas the dorsal amygdala, the region most commonly revealed by fMRI, may respond on the basis of arousal, ventral subregions may respond in a valencedependent manner).

There is evidence that some regions of the PFC also respond in a valence-independent way. In particular, some regions of the medial PFC have shown greater responses for both positive and negative stimuli than for neutral stimuli (Anders et al., 2004; Dolcos, LaBar, \& Cabeza, 2004; Lane, Fink, Chau, \& Dolan, 1997; Lane, Reiman, et al., 1997), and in some studies, large regions of the right 
PFC have been implicated in the processing of both positive and negative information (see Bowers, Bauer, Coslett, \& Heilman, 1985; Harrington, 1995; Hellige, 1993). The suggestion that the PFC responds in a valence-independent manner, however, has not been universally accepted, and there is ample evidence that many PFC regions respond differentially to positive and negative stimuli.

There have been two prevailing views regarding valencebased effects in the PFC. One is that the left hemisphere (and specifically, the left PFC) plays a disproportionate role in the processing of positive emotions, whereas the right hemisphere (and in particular, the right PFC) is dominant during the processing of negative emotions (see Davidson, 1995; Davidson \& Irwin, 1999). Evidence to support this valence-based laterality hypothesis has come mainly from lesion and electrophysiological studies. Patients with left-hemisphere lesions tend to show depressive symptoms, whereas patients with right-hemisphere lesions are more likely to show euphoria (e.g., Lee, Loring, Meader, \& Brooks, 1990; Morris et al., 1996; Paradiso, Chemerinski, Yazici, Tartaro, \& Robinson, 1999; Paradiso, Johnson, et al., 1999; Starkstein et al., 1989). Measures of electrophysiological activity have corroborated the hemispheric asymmetry based on valence: Individuals with high right frontal baseline activity report more negative affect and less positive affect than do individuals with higher left frontal baseline activity (e.g., George, Ketter, \& Post, 1993; Tomarken, Davidson, Wheeler, \& Doss, 1992), and event-related potentials are greater in the right hemisphere during the processing of negative stimuli and are greater in the left hemisphere during the processing of positive stimuli (e.g., Aftanas, Varlamov, Pavlov, Makhnev, \& Reva, 2001; Wheeler, Davidson, \& Tomarken, 1993). The functional neuroimaging literature, in contrast, has pro- vided only mixed support for this hypothesis. A few fMRI studies have provided evidence of a left/right distinction in the processing of positive and negative pictures (Canli, Desmond, Zhao, Glover, \& Gabrieli, 1998; Dolcos et al., 2004) or the generation of positive and negative emotion (Sutton et al., 1997), but others have not (e.g., Lane, Fink, et al., 1997; Schneider et al., 1995; Teasdale et al., 1999).

The second proposal, which has garnered its strongest support from neuroimaging investigations, is that lateral orbital PFC regions respond preferentially to negative stimuli, whereas ventromedial PFC regions respond preferentially to positive stimuli. Evidence supporting this hypothesis has come from studies in which the reward value of stimuli has been manipulated (e.g., by inducing satiety for a particular food): In these studies, as the stimulus became less rewarding, activity in the ventromedial PFC decreased, whereas activity in the orbitolateral PFC increased (Small, Zatorre, Dagher, Evans, \& Jones-Gotman, 2001; see also O’Doherty et al., 2000). A similar modulation of the PFC has been found on tasks varying monetary rewards and punishments: The ventromedial PFC has tended to show a greater response for rewards than for punishments, whereas the orbitolateral PFC has shown the opposite pattern of response (O'Doherty, Critchley, Deichmann, \& Dolan, 2003; O’Doherty, Kringelbach, Rolls, Hornak, \& Andrews, 2001).

In summary, the literature to date has suggested that the amygdala (at least the dorsal amygdala; Kim et al., 2003) may respond in an arousal-based fashion, whereas the PFC may respond in a valence-dependent manner. However, the specific effects of valence on PFC activity remain unclear. Moreover, because nearly all neuroimaging studies investigating the effects of valence and arousal on emotional processing have focused exclusively on the

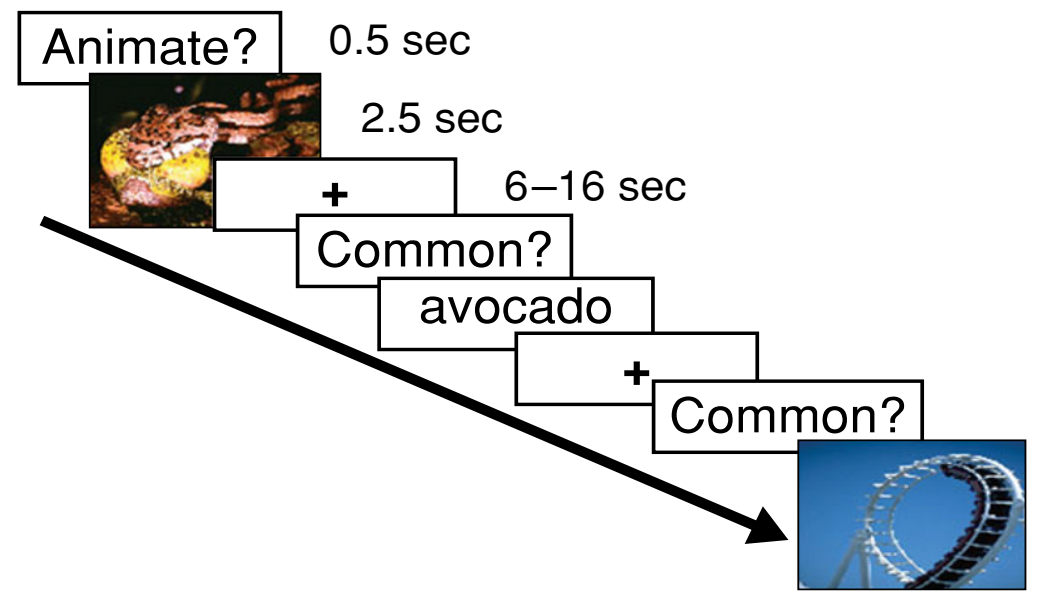

Figure 1. While in the scanner, the participants viewed positive, negative, and neutral pictures and words, each for $2.5 \mathrm{sec}$. Each stimulus was preceded by the prompt of "Animate?" or "Common?" indicating the question that the participants should answer regarding the stimulus: Did the stimulus depict or describe something animate, or did the stimulus depict or describe something that would be encountered within a typical month? Interstimulus intervals of 6-16 sec were interspersed between stimuli to provide jitter. 
amygdala or the PFC (but see Anders et al., 2004, who also examined activity in the insula, thalamus, and anterior parietal cortex), the full network of regions underlying arousal-related versus valence-dependent processing remains underspecified.

The first goal of the present study was to use wholebrain imaging to elucidate the network of regions that respond in an arousal-related manner (i.e., to all high- arousal stimuli, regardless of valence) versus in a valencerelated manner (i.e., preferentially to positive or negative stimuli). We also wanted to examine whether the arousaland valence-based patterns of activity demonstrated in prior experiments would extend to a paradigm in which participants were asked to judge stimuli for nonemotional factors (whether the stimulus described or depicted something animate/inanimate or something common/uncom-

Table 1

Regions That Showed a Greater Response to Positive Items Than to Neutral Items

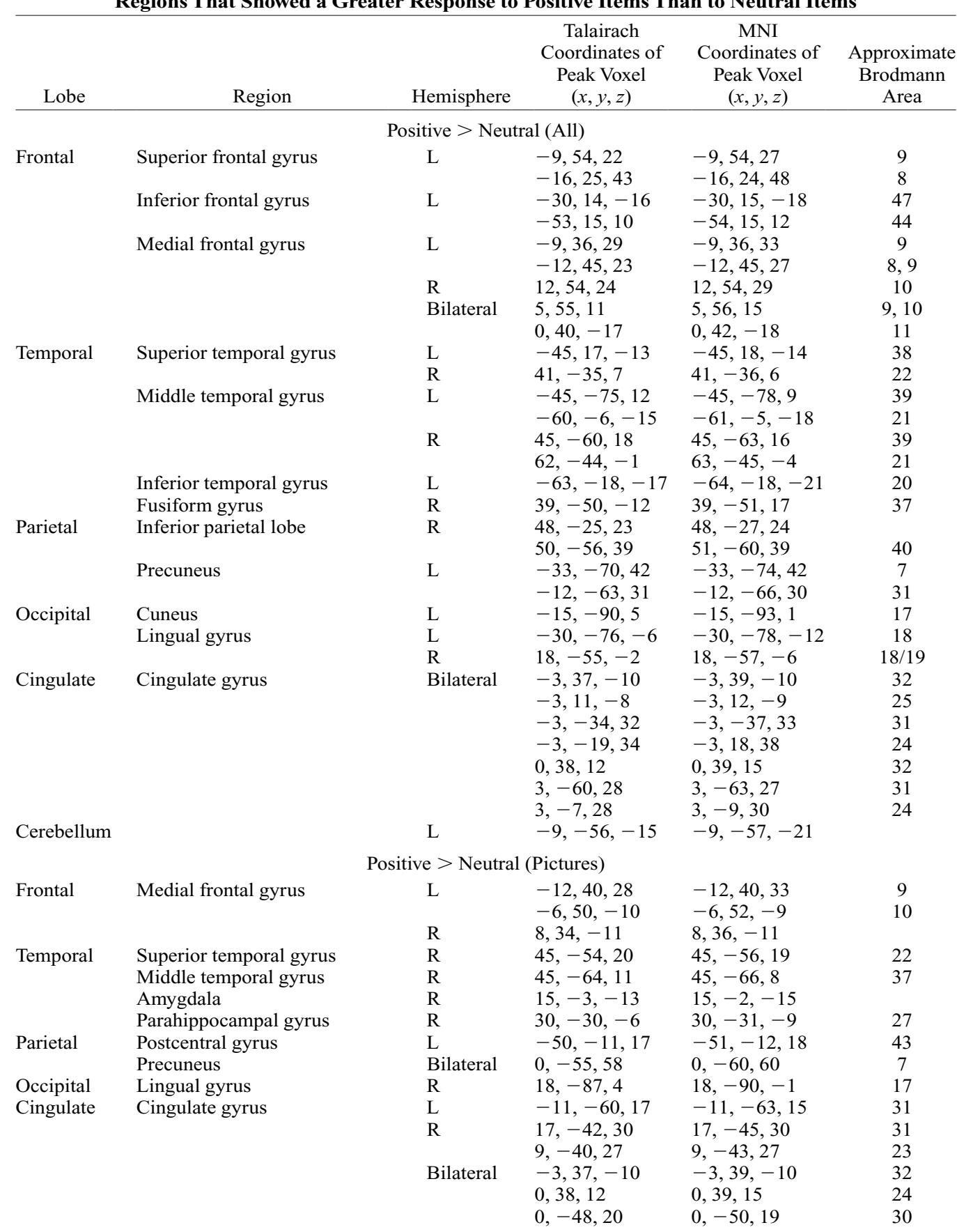


Table 1 (Continued)

\begin{tabular}{|c|c|c|c|c|c|}
\hline Lobe & Region & Hemisphere & $\begin{array}{c}\text { Talairach } \\
\text { Coordinates of } \\
\text { Peak Voxel } \\
(x, y, z)\end{array}$ & $\begin{array}{c}\text { MNI } \\
\text { Coordinates of } \\
\text { Peak Voxel } \\
(x, y, z)\end{array}$ & $\begin{array}{c}\text { Approximate } \\
\text { Brodmann } \\
\text { Area }\end{array}$ \\
\hline \multicolumn{6}{|c|}{ Positive $>$ Neutral (Words) } \\
\hline \multirow[t]{11}{*}{ Frontal } & Superior frontal gyrus & $\mathrm{L}$ & $-6,60,27$ & $-6,60,33$ & 9 \\
\hline & & & $-30,25,48$ & $-30,23,53$ & 8 \\
\hline & & & $-39,14,50$ & $-39,12,55$ & $6 / 8$ \\
\hline & Middle frontal gyrus & $\mathrm{L}$ & $-48,46,-2$ & $-48,47,0$ & 10 \\
\hline & & & $-45,16,27$ & $-45,15,30$ & $9 / 46$ \\
\hline & Inferior frontal gyrus & $\mathrm{L}$ & $-53,19,24$ & $-53,18,27$ & 45 \\
\hline & & & $-32,14,-13$ & $-32,15,-15$ & 47 \\
\hline & Medial frontal gyrus & $\mathrm{L}$ & $-8,48,22$ & $-8,48,26$ & 9 \\
\hline & & & $-6,62,16$ & $-6,63,26$ & 10 \\
\hline & & $\mathrm{R}$ & $8,62,21$ & $8,62,26$ & 10 \\
\hline & Precentral gyrus & $\mathrm{R}$ & $60,-16,40$ & $61,-19,43$ & 6 \\
\hline \multirow[t]{5}{*}{ Temporal } & Superior temporal gyrus & $\mathrm{L}$ & $-48,14,-11$ & $-48,15,-12$ & 38 \\
\hline & Middle temporal gyrus & $\mathrm{L}$ & $-62,-46,5$ & $-63,-48,3$ & 22 \\
\hline & & & $-53,-29,1$ & $-53,-30,-1$ & 21 \\
\hline & Inferior temporal gyrus & $\mathrm{L}$ & $-62,-15,-14$ & $-63,-15,-18$ & $21 / 22$ \\
\hline & Fusiform gyrus & $\mathrm{R}$ & $39,-50,-15$ & $39,-51,-21$ & 37 \\
\hline \multirow[t]{5}{*}{ Parietal } & Superior parietal lobe & $\mathrm{L}$ & $-30,-67,50$ & $-30,-72,51$ & 7 \\
\hline & Inferior parietal lobe & $\mathrm{L}$ & $-54,-48,24$ & $-55,-50,23$ & 40 \\
\hline & & $\mathrm{R}$ & $45,-56,47$ & $45,-60,48$ & $7 / 40$ \\
\hline & Postcentral gyrus & $\mathrm{R}$ & $48,-15,40$ & $48,-18,43$ & 3 \\
\hline & Precuneus/angular gyrus & $\mathrm{L}$ & $-45,-65,34$ & $-45,-69,33$ & 39 \\
\hline Occipital & Inferior/middle occipital gyrus & $\mathrm{R}$ & $36,-79,-6$ & $36,-81,-12$ & $18 / 19$ \\
\hline \multirow[t]{4}{*}{ Cingulate } & Cingulate gyrus & Bilateral & $-3,36,23$ & $-3,36,27$ & 32 \\
\hline & & & $3,39,17$ & $3,39,21$ & 32 \\
\hline & & & $0,-33,32$ & $0,-36,33$ & 31 \\
\hline & & & $0,-48,22$ & $0,-50,21$ & $23 / 30$ \\
\hline \multirow[t]{2}{*}{ Cerebellum } & & $\mathrm{L}$ & $-14,-56,-20$ & $-14,-57,-27$ & \\
\hline & Caudate & $\mathrm{L}$ & $-15,12,10$ & $-15,12,12$ & \\
\hline
\end{tabular}

mon). If we think of the requirement for monitoring emotional responses as being on a continuum, prior studies examining valence and arousal effects have been closer to the high-monitoring end of the spectrum than to the lowmonitoring end. Some of the tasks have required explicit regulation of emotion, asking participants to experience the emotion elicited and to make a pleasantness rating (Dolcos et al., 2004). Other studies, although not requiring explicit reporting of the emotional reaction, have nevertheless emphasized that participants should attend to their emotional responses to the stimuli (e.g., "pay attention and experience whatever thoughts or feelings the pictures may elicit in you"; Hamann et al., 2002). A number of studies have suggested that the processes engaged while an emotional experience is monitored or labeled may be distinct from those typically recruited during the processing of emotional information (e.g., Cunningham, Raye, \& Johnson, 2004; Hariri, Bookheimer, \& Mazziotta, 2000; Lane, Fink, et al., 1997; Lane, Reiman, et al., 1997; Lange et al., 2003; Taylor, Phan, Decker, \& Liberzon, 2003; but see Hutcherson et al., 2005, for evidence that monitoring and reporting an emotional response may not have robust effects on behavioral performance or neural activity). Thus, we wanted to examine whether distinct arousaland valence-based responses would still be apparent when participants performed a task that did not require monitoring of an emotional response.
The second goal of the present study was to examine whether the stimulus type (picture or word) would affect the pattern of arousal-related and valence-dependent responses. To our knowledge, no study has compared the arousal- and valence-based processing of two different types of emotional stimuli within the same paradigm (but see Royet et al., 2000, for a comparison of emotionally valenced olfactory, visual, and auditory stimuli). By assessing the neural responses to emotional pictures and words, we could examine the extent to which valencedependent and arousal-based processing overlapped for the two stimulus classes. We were particularly interested in whether the stimulus type would affect the pattern of response in the amygdala: Although there is some evidence, from cross-study comparisons, that the amygdala responds to high-arousal stimuli across a range of modalities and stimulus types (Anderson et al., 2003; Garavan et al., 2001; Hamann et al., 2002; Small et al., 2003), differences in image acquisition methods make it difficult to determine whether it is the same amygdala subregions that respond or whether distinct regions respond on the basis of the type of information being processed. As a corollary of this second goal, we examined whether valence or stimulus type would affect the laterality of amygdala recruitment. Although some research has suggested that the amygdala may respond in a stimulus-specific manner (i.e., the left amygdala responding to words, and the right 
Table 2

Regions That Showed a Greater Response to Negative Items Than to Neutral Items

\begin{tabular}{|c|c|c|c|c|c|}
\hline Lobe & Region & Hemisphere & $\begin{array}{c}\text { Talairach } \\
\text { Coordinates of } \\
\text { Peak Voxel } \\
(x, y, z)\end{array}$ & $\begin{array}{c}\text { MNI } \\
\text { Coordinates of } \\
\text { Peak Voxel } \\
(x, y, z)\end{array}$ & $\begin{array}{c}\text { Approximate } \\
\text { Brodmann } \\
\text { Area }\end{array}$ \\
\hline \multicolumn{6}{|c|}{ Negative $>$ Neutral (All) } \\
\hline \multirow[t]{6}{*}{ Frontal } & Superior frontal gyrus & Bilateral & $\begin{array}{l}-3,62,22 \\
0,56,28\end{array}$ & $\begin{array}{l}-3,63,28 \\
0,56,33\end{array}$ & $\begin{array}{l}9 / 10 \\
9 / 10\end{array}$ \\
\hline & Inferior frontal gyrus & $\mathrm{L}$ & $-42,20,-14$ & $-42,21,-15$ & 47 \\
\hline & & $\mathrm{L}$ & $-45,18,13$ & $-45,18,15$ & 45 \\
\hline & & $\mathrm{R}$ & $53,23,2$ & $54,24,3$ & 47 \\
\hline & Medial frontal gyrus & Bilateral & $-3,43,-14$ & $-3,45,-14$ & 11 \\
\hline & & & $0,54,-10$ & $0,56,-9$ & 10 \\
\hline \multirow[t]{10}{*}{ Temporal } & Superior temporal gyrus & $\mathrm{L}$ & $-56,-60,14$ & $-56,-62,12$ & 39 \\
\hline & & & $-50,11,-18$ & $-50,12,-21$ & 38 \\
\hline & & $\mathrm{R}$ & $62,-46,10$ & $63,-48,8$ & 22 \\
\hline & & & $44,-43,18$ & $44,-45,17$ & 13 \\
\hline & Middle temporal gyrus & $\mathrm{L}$ & $-51,-6,-15$ & $-51,-7,16$ & 21 \\
\hline & & $\mathrm{R}$ & $50,-60,16$ & $50,-63,14$ & 19 \\
\hline & & & $53,-69,20$ & $54,-72,18$ & 39 \\
\hline & & & $56,5,-15$ & $56,6,-18$ & 21 \\
\hline & Inferior temporal gyrus & $\mathrm{R}$ & $62,-7,-17$ & $63,-6,-21$ & 21 \\
\hline & Amygdala & $\mathrm{L}$ & $-21,-6,-17$ & $21,-5,-21$ & \\
\hline \multirow[t]{5}{*}{ Parietal } & Precuneus & Bilateral & $3,-57,30$ & $3,-60,30$ & 7 \\
\hline & & & $-3,-62,36$ & $-3,-66,36$ & 7 \\
\hline & Inferior parietal lobe & $\mathrm{R}$ & $56,-42,24$ & $57,-45,24$ & 40 \\
\hline & Cingulate gyrus & Bilateral & $0,-45,27$ & $0,-48,27$ & \\
\hline & & Negative $>\mathrm{Ne}$ & atral (Pictures) & & \\
\hline \multirow[t]{6}{*}{ Frontal } & Superior frontal gyrus & Bilateral & $3,54,27$ & $3,54,32$ & 9 \\
\hline & Inferior frontal gyrus & $\mathrm{L}$ & $-48,15,15$ & $-48,15,17$ & $44 / 45$ \\
\hline & & & $-33,13,-18$ & $-33,14,-21$ & 47 \\
\hline & & $\mathrm{R}$ & $53,23,2$ & $53,24,3$ & 47 \\
\hline & & & $56,30,9$ & $57,30,11$ & 45 \\
\hline & Medial frontal gyrus & $\mathrm{L}$ & $-3,43,-12$ & $-3,45,-12$ & 10 \\
\hline \multirow[t]{9}{*}{ Temporal } & Superior temporal gyrus & $\mathrm{L}$ & $-50,-55,16$ & $-50,-57,14$ & 39 \\
\hline & & & $-45,16,-26$ & $-45,18,-30$ & 38 \\
\hline & Middle temporal gyrus & $\mathrm{L}$ & $-38,-75,25$ & $-38,-79,23$ & 39 \\
\hline & & $\mathrm{R}$ & $50,-60,17$ & $51,-63,15$ & 19 \\
\hline & Fusiform gyrus & $\mathrm{L}$ & $-41,-44,-15$ & $-41,-45,-20$ & 37 \\
\hline & & $\mathrm{R}$ & $39,-53,-7$ & $39,-54,-11$ & 37 \\
\hline & Amygdala & $\mathrm{L}$ & $-21,-3,-12$ & $-21,-3,-14$ & \\
\hline & & & $-23,-8,-10$ & $-23,-8,-12$ & \\
\hline & & $\mathrm{R}$ & $20,-4,-17$ & $20,-3,-20$ & \\
\hline \multirow[t]{6}{*}{ Occipital } & Middle occipital gyrus & $\mathrm{R}$ & $42,-64,1$ & $42,-66,-3$ & 37 \\
\hline & Cingulate gyrus & Bilateral & $11,-49,19$ & $11,-51,18$ & $23 / 30$ \\
\hline & & & $2,20,-6$ & $2,21,-6$ & $24 / 25$ \\
\hline & Thalamus & $\mathrm{L}$ & $-12,-11,6$ & $-12,-12,6$ & \\
\hline & Hypothalamus & $\mathrm{R}$ & $12,-3,-7$ & $12,-3,-9$ & \\
\hline & & Negative $>\mathrm{N}$ & utral (Words) & & \\
\hline \multirow[t]{5}{*}{ Frontal } & Superior frontal gyrus & $\mathrm{L}$ & $-9,60,27$ & $-9,60,33$ & $9 / 10$ \\
\hline & & $\mathrm{R}$ & $0,57,27$ & $0,57,32$ & $9 / 10$ \\
\hline & Inferior frontal gyrus & $\mathrm{L}$ & $-53,27,18$ & $-54,27,21$ & 46 \\
\hline & & & $-45,20,-11$ & $-45,21,-12$ & 47 \\
\hline & & & $-44,37,-14$ & $-44,39,-14$ & 11 \\
\hline \multirow[t]{6}{*}{ Temporal } & Superior temporal gyrus & $\mathrm{L}$ & $-51,-45,19$ & $-51,-47,18$ & 22 \\
\hline & & & $-36,13,-21$ & $-36,14,-24$ & 38 \\
\hline & & $\mathrm{R}$ & $35,14,-23$ & $35,16,-27$ & 38 \\
\hline & Middle temporal gyrus & $\mathrm{L}$ & $-56,-52,10$ & $-56,-54,8$ & 39 \\
\hline & & $\mathrm{R}$ & $53,-26,-1$ & $54,-27,-3$ & $21 / 22$ \\
\hline & Amygdala & $\mathrm{L}$ & $-26,0,-20$ & $-26,1,-24$ & \\
\hline \multirow[t]{2}{*}{ Parietal } & Precuneus & $\mathrm{L}$ & $-3,-62,36$ & $-3,-66,36$ & 7 \\
\hline & Cingulate gyrus & Bilateral & $0,-45,27$ & $0,-48,27$ & 31 \\
\hline
\end{tabular}


amygdala responding to pictures; see Markowitsch, 1998), to our knowledge, this hypothesis has not been directly assessed, and there are a number of other hypotheses regarding laterality effects in the amygdala (see Baas et al., 2004; Cahill, 2003; Glascher \& Adolphs, 2003; Phelps et al., 2001).

\section{METHOD}

\section{Participants}

The participants were 21 young adults $(11 \mathrm{men})$ between the ages of 18 and 35 years. All were right-handed native English speakers with no history of psychiatric or neurological disorders. No participant was taking any medication that would affect the central nervous system, and no participant was depressed. Informed consent was obtained from all the participants in a manner approved by the Harvard University and Massachusetts General Hospital Institutional Review Boards.

\section{Materials}

Stimuli included 360 words (120 positive and arousing, 120 negative and arousing, and 120 neutral) and 360 pictures (120 positive and arousing, 120 negative and arousing, and 120 neutral). Words were selected from the ANEW database (Bradley \& Lang, 1999) and were supplemented with additional neutral words. Pictures were selected from the IAPS database (Lang, Bradley, \& Cuthbert, 1997) and were supplemented with additional neutral pictures. The words and pictures were chosen so that positive and negative words, and positive and negative pictures, were equated in arousal and in absolute valence (i.e., distance from neutral valence). In a separate testing session, conducted after completion of the fMRI study, the participants rated the stimuli for valence and arousal. The ratings generally agreed with those from the ANEW and IAPS databases.
Neutral pictures received a mean valence rating of $5.22(S D=0.64)$ and a mean arousal rating of $3.45(S D=0.77)$, whereas neutral words received a valence rating of $4.89(S D=0.91)$ and a mean arousal rating of $3.59(S D=0.30)$. Negative pictures received a mean valence rating of $2.76(S D=0.75)$ and a mean arousal rating of $5.83(S D=0.77)$, whereas negative words received a mean valence rating of $2.89(S D=1.10)$ and a mean arousal rating of $5.58(S D=0.46)$. Positive pictures received a mean valence rating of $6.99(S D=0.66)$ and a mean arousal rating of $5.89(S D=$ $0.75)$, whereas positive words received a mean valence rating of 6.67 $(S D=0.69)$ and a mean arousal rating of $5.58(S D=0.62)$. In the rare instances in which the participants' ratings did not agree with the normative data ( $<1 \%$ of all responses), the items in question were not included in the analyses for that participant.

Positive, negative, and neutral words were matched in frequency, familiarity, imageability, and word length, as determined by normative data in the ANEW database (Bradley \& Lang, 1999) and in the MRC psycholinguistic database (Coltheart, 1981). Positive, negative, and neutral pictures were matched for visual complexity (as rated by 5 young adults who did not participate in the MRI study; they were instructed that high scene complexity could be based on "the number of objects, scene details, or colors present in a scene, visual clutter, asymmetry, lack of open spaces, or lack of organization"; see Oliva, Mack, Shrestha, \& Peeper, 2004), brightness (as assessed via Adobe Photoshop), and the number of stimuli that included people, animals, or buildings and landscapes. In addition, because the participants were asked to determine whether words and pictures described or depicted something (1) animate or (2) common (see below), the stimuli were selected so that roughly half of the stimuli from each emotion category received a "yes" response to each question.

\section{Procedure}

The participants were scanned as they viewed 180 words and 180 pictures (60 from each emotional category; see Figure 1). Each word
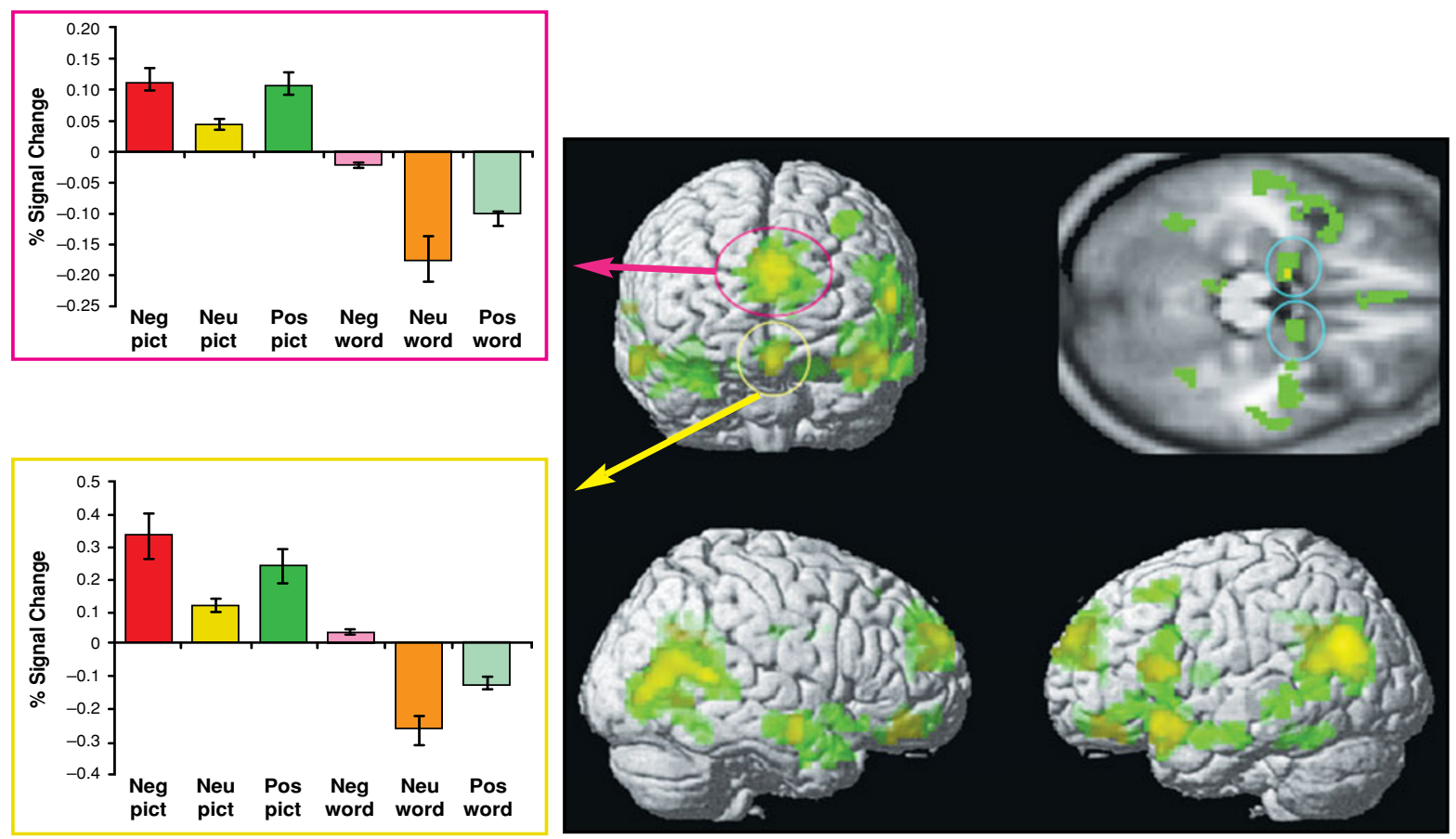

Figure 2. Arousal responses (negative $>$ neutral and positive $>$ neutral), collapsing across pictures and words. Both the dorsomedial prefrontal cortex (PFC; circled in pink) and the ventromedial PFC (circled in yellow) showed an arousalrelated response, as did the amygdala (see Figure 4 for time courses in the amygdala). 
or picture was presented for $2,500 \mathrm{msec}$. Preceding half of the stimuli was the prompt "Animate?"; the prompt "Common?" preceded the remaining stimuli. The prompt was presented for $500 \mathrm{msec}$ and indicated the question that the participants should answer as they viewed the upcoming stimulus. The participants were instructed to respond "yes" to the "Animate?" prompt if a picture included an animate element or if a word described something animate (either the name of something animate [e.g., a snake] or a word that would generally be used in reference to something animate [e.g., laugh]) and otherwise to respond "no." The participants were asked to respond "yes" to the "Common?" prompt if the stimulus depicted or described something that they would encounter in a typical month. ${ }^{1}$ Emotional processing did not differ on the basis of task (judgments of animacy vs. commonality), so all the reported results collapse across the two tasks. Words and pictures from the different emotion categories and prompt conditions were pseudorandomly intermixed, with interstimulus intervals (ISI) ranging from 6 to $16 \mathrm{sec}$. This design created jitter (Dale, 1999), and in addition, pilot data indicated that this ISI was sufficient to allow the emotional response to one item to dissipate before presentation of the next item.

\section{Image Acquisition and Data Analysis}

Images were acquired on a 1.5 Tesla Siemens Sonata MRI scanner. Stimuli were back-projected onto a screen in the scanner bore, and the participants viewed the words through an angled mirror attached to the head coil. Detailed anatomic images were acquired using a multiplanar rapidly acquired gradient echo (MP-RAGE) sequence. Functional images were acquired using a T2*-weighted echo planar imaging sequence $(\mathrm{TR}=3,000 \mathrm{msec}, \mathrm{TE}=40 \mathrm{msec}$, FOV $=200 \mathrm{~mm}$, flip angle $=90^{\circ}$ ). Twenty-nine axial-oblique slices (3.12-mm thickness, 0.6-mm skip between slices), aligned in a plane along the axis connecting the anterior commisure and the posterior commisure, were acquired in an interleaved fashion.

All preprocessing and data analysis were conducted within SPM99 (Wellcome Department of Cognitive Neurology). Standard preprocessing was performed on the functional data, including slice-

Table 3

Regions That Showed an Arousal-Related Response: Greater Activity for Positive Items Than for Neutral Items and for Negative Items Than for Neutral Items

\begin{tabular}{|c|c|c|c|c|c|}
\hline Lobe & Region & Hemisphere & $\begin{array}{c}\text { Talairach } \\
\text { Coordinates of } \\
\text { Peak Voxel } \\
(x, y, z)\end{array}$ & $\begin{array}{c}\text { MNI } \\
\text { Coordinates of } \\
\text { Peak Voxel } \\
(x, y, z) \\
\end{array}$ & $\begin{array}{c}\text { Approximate } \\
\text { Brodmann } \\
\text { Area } \\
\end{array}$ \\
\hline \multicolumn{6}{|c|}{ Negative $>$ Neutral and Positive $>$ Neutral (All) } \\
\hline \multirow[t]{5}{*}{ Frontal } & Superior frontal gyrus & $\mathrm{L}$ & $-9,54,22$ & $-9,54,27$ & 9 \\
\hline & & $\mathrm{R}$ & $3,54,28$ & $3,54,33$ & 9 \\
\hline & Inferior frontal gyrus & $\mathrm{L}$ & $-30,14,-16$ & $-30,15,-18$ & 47 \\
\hline & Medial frontal oyrus & & $-54,15,10$ & $-54,15,12$ & $\begin{array}{l}44 \\
10\end{array}$ \\
\hline & Medial frontal gyrus & Bilateral & $\begin{array}{l}0,60,16 \\
0,40,-17\end{array}$ & $\begin{array}{l}0,61,20 \\
0,42,-18\end{array}$ & $\begin{array}{l}10 \\
11\end{array}$ \\
\hline \multirow[t]{8}{*}{ Temporal } & Superior temporal gyrus & $\mathrm{L}$ & $-45,17,-13$ & $-45,18,-14$ & 38 \\
\hline & & $\mathrm{R}$ & $56,-43,10$ & $57,-45,9$ & $21 / 22$ \\
\hline & Middle temporal gyrus & $\mathrm{L}$ & $-48,-70,12$ & $-48,-73,9$ & 39 \\
\hline & & $\mathrm{R}$ & $63,-6,-15$ & $63,-5,-18$ & 21 \\
\hline & Fusiform gyrus & $\mathrm{L}$ & $-39,-53,-15$ & $-39,-54,-21$ & 37 \\
\hline & Amygdala & $\mathrm{L}$ & $-15,-4,-18$ & $-15,-3,-21$ & \\
\hline & & $\mathrm{R}$ & $28,-1,-17$ & $28,0,-20$ & \\
\hline & & & $15,-1,-17$ & $15,0,-20$ & \\
\hline Occipital & Middle occipital gyrus & $\mathrm{R}$ & $48,-73,6$ & $48,-75,3$ & 37 \\
\hline \multirow[t]{3}{*}{ Cingulate } & Cingulate gyrus & Bilateral & $3,-60,28$ & $3,-63,27$ & 31 \\
\hline & & & $0,-45,22$ & $0,-47,21$ & $23 / 30$ \\
\hline & Putamen & $\mathrm{L}$ & $-21,1,11$ & $-21,0,12$ & \\
\hline \multicolumn{6}{|c|}{ Negative $>$ Neutral and Positive $>$ Neutral (Pictures) } \\
\hline Frontal & Medial frontal gyrus & Bilateral & $\begin{array}{l}6,51,28 \\
-3,52,-10\end{array}$ & $\begin{array}{l}6,51,33 \\
-3,54,-9\end{array}$ & $\begin{array}{c}9 \\
10,11\end{array}$ \\
\hline \multirow[t]{9}{*}{ Temporal } & Superior temporal gyrus & $\mathrm{R}$ & $45,-54,20$ & $45,-56,19$ & 22 \\
\hline & Middle temporal gyrus & $\mathrm{R}$ & $45,-64,11$ & $45,-66,9$ & 37 \\
\hline & & & $\underline{60,-45,2}$ & $\underline{61,-46,0}$ & 22 \\
\hline & & & $\underline{53,-6,-10}$ & $\underline{54,-6,-12}$ & 21,38 \\
\hline & Fusiform gyrus & $\mathrm{R}$ & $48,-7,-22$ & $48,-6,-27$ & 20 \\
\hline & Amygdala & $\mathrm{R}$ & $\underline{15,-3,-15}$ & $15,-2,-18$ & \\
\hline & & & $25,-1,-17$ & $25,0,-20$ & \\
\hline & Parahippocampal gyrus & $\mathrm{R}$ & $30,-30,-6$ & $30,-30,-9$ & 27 \\
\hline & & & $24,-36,-11$ & $24,-37,-15$ & 35 \\
\hline Parietal & Precuneus & Bilateral & $6,-45,50$ & $6,-49,52$ & 7 \\
\hline \multirow[t]{6}{*}{ Occipital } & Middle occipital gyrus & $\mathrm{R}$ & $\underline{48,-72,6}$ & $\underline{48,-74,3}$ & 19 \\
\hline & Cingulate gyrus & $\mathrm{R}$ & $12,-49,14$ & $12,-51,13$ & 23,30 \\
\hline & & Bilateral & $\underline{0,-39,30}$ & $\underline{0,-42,30}$ & 31 \\
\hline & & & $\underline{0,39,12}$ & $\underline{0,40,15}$ & 24,32 \\
\hline & & & $-3,37,-9$ & $-3,39,-8$ & 32 \\
\hline & & & $-3,4,30$ & $-3,3,33$ & 24 \\
\hline
\end{tabular}


Table 3 (Continued)

\begin{tabular}{|c|c|c|c|c|c|}
\hline Lobe & Region & Hemisphere & $\begin{array}{c}\text { Talairach } \\
\text { Coordinates of } \\
\text { Peak Voxel } \\
(x, y, z)\end{array}$ & $\begin{array}{c}\text { MNI } \\
\text { Coordinates of } \\
\text { Peak Voxel } \\
(x, y, z) \\
\end{array}$ & $\begin{array}{c}\text { Approximate } \\
\text { Brodmann } \\
\text { Area }\end{array}$ \\
\hline \multicolumn{6}{|c|}{ Negative $>$ Neutral and Positive $>$ Neutral (Words) } \\
\hline \multirow[t]{11}{*}{ Frontal } & Superior frontal gyrus & $\mathrm{L}$ & $\begin{array}{l}-6,60,27 \\
-39,22,49\end{array}$ & $\begin{array}{l}-6,60,33 \\
-39,20,54\end{array}$ & $\begin{array}{c}9,10 \\
6,8\end{array}$ \\
\hline & Middle frontal gyrus & $\mathrm{L}$ & $-48,40,-10$ & $-48,42,-10$ & 11 \\
\hline & & & $-39,14,50$ & $-39,12,55$ & 6 \\
\hline & & & $-45,19,27$ & $-45,19,30$ & $9 / 46$ \\
\hline & Inferior frontal gyrus & $\mathrm{L}$ & $-54,19,24$ & $-54,18,27$ & 45,9 \\
\hline & & & $-48,18,5$ & $-48,18,6$ & 45,47 \\
\hline & & & $-45,20,-11$ & $-45,21,-12$ & 47 \\
\hline & & & $-56,18,10$ & $-56,18,12$ & 44 \\
\hline & Medial frontal gyrus & Bilateral & $0,40,-17$ & $\overline{0,42,-18}$ & 11 \\
\hline & & & $-3,43,37$ & $-3,42,43$ & 6 \\
\hline & & & $\overline{-6,65,16}$ & $-6,66,21$ & 10 \\
\hline \multirow[t]{8}{*}{ Temporal } & Superior temporal gyrus & $\mathrm{L}$ & $-48,14,-11$ & $-48,15,-12$ & 38 \\
\hline & & & $-42,10,-31$ & $-42,12,-36$ & 38 \\
\hline & & & $-50,2,-10$ & $-51,3,-12$ & 21 \\
\hline & & $\mathrm{R}$ & $39,-43,13$ & $39,-45,12$ & 22 \\
\hline & Middle temporal gyrus & $\mathrm{L}$ & $-60,-50,8$ & $-60,-42,7$ & $22 / 39$ \\
\hline & & & $-60,-30,1$ & $-60,-31,0$ & $21 / 22$ \\
\hline & & $\mathrm{R}$ & $53,-27,-1$ & $53,-28,-3$ & $21 / 22$ \\
\hline & Amygdala & $\mathrm{L}$ & $-25,-4,-17$ & $-25,-3,-20$ & \\
\hline \multirow[t]{3}{*}{ Parietal } & Superior parietal lobe & $\mathrm{L}$ & $-39,-64,48$ & $\overline{-39,-68,49}$ & 7 \\
\hline & Inferior parietal lobe & $\mathrm{L}$ & $-42,-65,47$ & $-42,-69,47$ & $7 / 40$ \\
\hline & Precuneus & $\mathrm{L}$ & $-3,-60,39$ & $-3,-64,39$ & 7 \\
\hline Occipital & Inferior/middle occipital gyrus & $\mathrm{R}$ & $\underline{48,-78,-1}$ & $\underline{48,-80,-6}$ & 18,19 \\
\hline \multirow[t]{4}{*}{ Cingulate } & Cingulate gyrus & Bilateral & $0,-45,30$ & $0,-48,30$ & 31 \\
\hline & & & $0,-49,21$ & $0,-51,20$ & $23 / 30$ \\
\hline & & & $\underline{3,-19,31}$ & $3,-21,33$ & 23 \\
\hline & & & $3,-2,28$ & $3,-4,30$ & 24 \\
\hline Cerebellum & & & $-6,-56,-15$ & $-6,-57,-21$ & \\
\hline
\end{tabular}

timing correction, rigid body motion correction, normalization to the Montreal Neurological Institute template (resampling at $3 \mathrm{~mm}$ cubic voxels), and spatial smoothing (using an 8-mm full-width half maximum isotropic Gaussian kernel).

For each participant, and on a voxel-by-voxel basis, an event-related analysis was first conducted in which all instances of a particular event type were modeled through convolution with a canonical hemodynamic response function. Effects for each event type were estimated using a subject-specific, fixed-effects model. These data were then entered into a second-order, random effects analysis. Contrast analyses were performed to examine effects of valence (positive vs. negative); one-sample $t$ tests were used to examine the consistency of activity at each voxel (using between-participants variability to estimate variance). An individual voxel threshold of $p<.01$ with a cluster threshold of 19 contiguous voxels was used to yield results corrected for multiple comparisons to $p<.05$ (see Slotnick, Moo, Segal, $\&$ Hart, 2003). Conjunction analyses, using the masking function in SPM99, examined the regions shared between two contrasts. The results for these conjunction analyses are presented in two ways: with the individual contrasts included in the contrast analysis analyzed at a threshold of $p<.01$ and with a voxel extent of 10 voxels (so that the conjoint probability of the conjunction analysis, using Fisher's estimate [Fisher, 1950; Lazar, Luna, Sweeney, \& Eddy, 2002], was $p<.001)$ and with the contrasts analyzed at a more lenient threshold $(p<.05)$ but with a larger voxel extent (20 voxels). ${ }^{2}$

All activations are presented in neurological coordinates (i.e., activity on the right hemisphere is presented on the right side of the brain images). Voxel coordinates are reported in Talairach coordinates (Talai- rach \& Tournoux, 1988) and in Montreal Neurological Institute (MNI) coordinates (Collins et al., 1998) and reflect the most significant voxel within the cluster of activation. Event-related time courses were extracted from active clusters by creating regions-of-interest (ROIs) as 8-mm spheres, using the ROI toolbox implemented in SPM99.

\section{RESULTS}

Analyses were conducted to identify the regions that responded to all high-arousal stimuli, regardless of valence, versus in a valence-dependent manner. These analyses were conducted separately for all the stimuli (collapsing across pictures and words), for pictures only, and for words only. Thus, we could examine the extent to which stimulus type affected the pattern of responses.

\section{Arousal Responses}

We first collapsed across pictures and words to examine the regions in which activity was enhanced for positive, in comparison with neutral, stimuli and for negative, in comparison with neutral, stimuli (i.e., positive $>$ neutral and negative $>$ neutral; see Tables 1 and 2 for regions identified in each of these separate contrasts). ${ }^{3}$ The regions revealed by this conjunction analysis were those that responded to all high-arousal items, regardless 
of valence (see Figure 2; yellow indicates regions identified when individual contrasts were analyzed at $p<.01$ with a 10-voxel extent; green indicates regions identified when individual contrasts were analyzed at $p<.05$ with a 20-voxel extent). Consistent with prior findings (Dolcos et al., 2004; Hamann et al., 2002), activity in the dorsomedial PFC (Figure 2, region outlined in pink; Talairach coordinates 3, 54, 28; BA 9/10) and in the amygdala bilaterally (Figure 2, region outlined in blue; Talairach coordinates $-15,-4,-18 ; 15,-1,-17)$ showed this arousalrelated pattern of response. In addition, a second region of the medial PFC, in a very ventral portion (Figure 2, region outlined in yellow; Talairach coordinates 0,40 , -17 ; BA 11) also showed this arousal-based activity, as did a large portion of the anterior temporal lobe, a region spanning the temporo-occipital junction, and a portion of the left dorsolateral PFC (see Table 3).

We then examined whether these arousal responses were consistent when analyses were conducted separately for pictures and words. When the conjunction analysis was conducted only for pictures, the results looked very similar to those discussed for all stimuli (Figure 3, panel A): Activity in the same two medial PFC regions (outlined in pink and yellow; Talairach coordinates 6, 51, 28 [BA 9] and $-3,52,-10$, [BA 10 and 11]) and in the amygdala bilaterally (outlined in blue; Talairach coordinates $15,-3$, $-15 ; 25,-1,-17)$ corresponded with arousal-related activity, as did activity in the anterior temporal lobe and in a region spanning the temporo-parietal junction (see Table 3). For the pictures, however, the activity in the latter two regions was strongest in the right hemisphere (as depicted in Figure 3).

When arousal-related activity for the words was analyzed (Figure 3, panel B), the same two regions of the medial PFC (outlined in pink and yellow; Talairach coordinates -6, 60, 27 [BA 9 and 10] and 0, 40, - 17 [BA 11]) were identified. Amygdala activity also corresponded with arousal-related activity, but the activation was lateralized to the left (outlined in blue; Talairach coordinates $-25,-4,-17)$. In addition, although there was activity in the anterior temporal lobe and in the temporo-occipital junction, this activity was stronger in the left hemisphere than in the right hemisphere [a pattern of laterality opposite to that demonstrated when only pictures were analyzed, as depicted in Figure 3 and as confirmed by a significant interaction between stimulus type and laterality on the arousal-related signal change throughout the lateral temporal lobe; $F(1,19)=8.13, p<.01]$. Thus, the general arousal-based patterns of activation (in two regions of the medial PFC and in the amygdala) were comparable for both pictures and words (see Table 3 ).

\section{Laterality of Amygdala Activation}

The results described above indicated that although the general patterns of arousal-related activity were comparable for pictures and for words, laterality effects throughout the temporal lobe, including those in the amygdala, may arise from stimulus-specific effects, with pictures lead- ing to stronger right-lateralized activity and words leading to stronger left-lateralized activity. To further explore the factors that contributed to the laterality effects in the amygdala, we defined regions in the left and right amygdala functionally, from an analysis contrasting activity for positive and negative stimuli with activity for neutral stimuli (i.e., positive pictures + positive words + negative pictures + negative words $>$ neutral pictures + neutral words). ${ }^{4}$ This analysis was, therefore, unbiased with regard to whether the activity in the amygdala was influenced by stimulus type (picture or word) or stimulus valence (positive or negative). For both of the amygdalar regions, we extracted the peak signal change (i.e., the maximum signal change, from baseline, along the time course).

As is shown in Figure 4, the left amygdala showed arousal-related activity for both pictures and words,
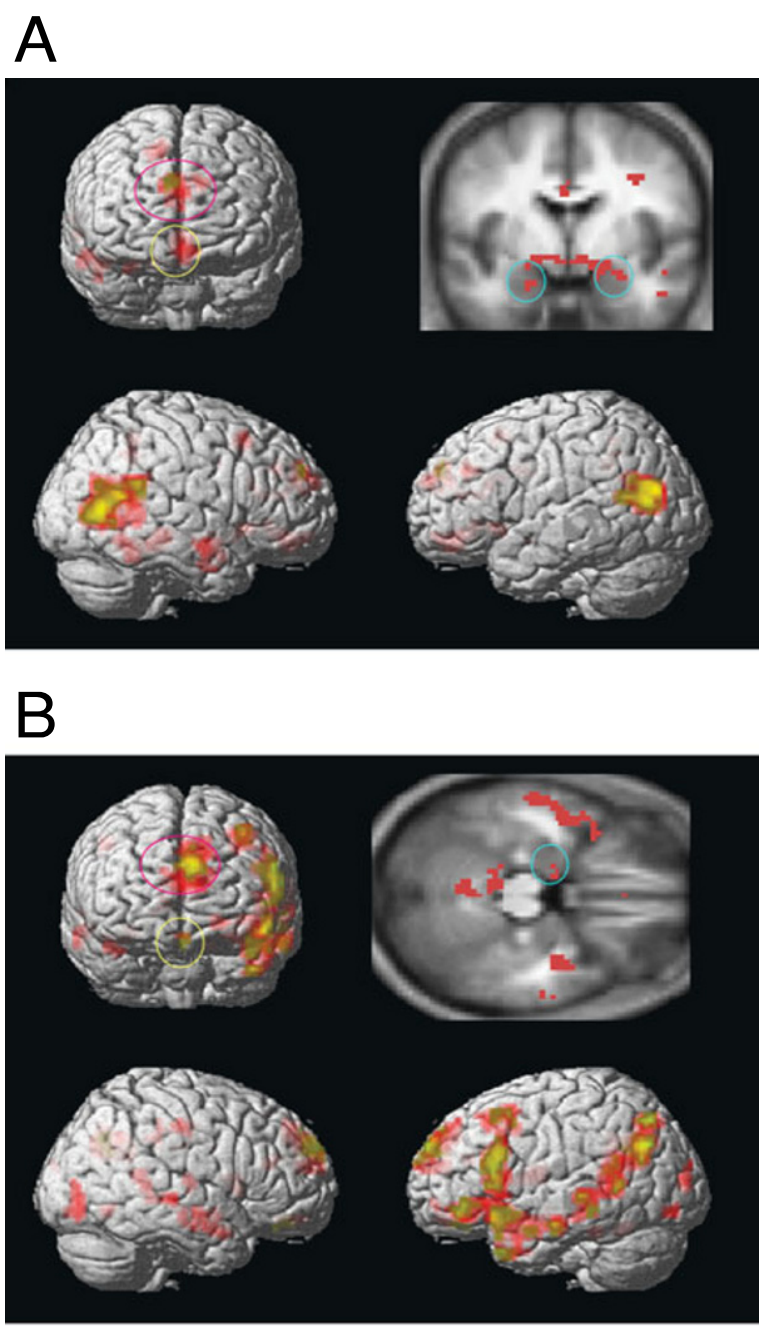

Figure 3. Arousal responses (negative $>$ neutral and positive $>$ neutral) for (A) pictures and (B) words. For both stimulus types, arousal-related activity occurred in the dorsomedial prefrontal cortex (PFC; outlined in pink), in the ventromedial PFC (outlined in yellow), and in the amygdala (outlined in blue). 

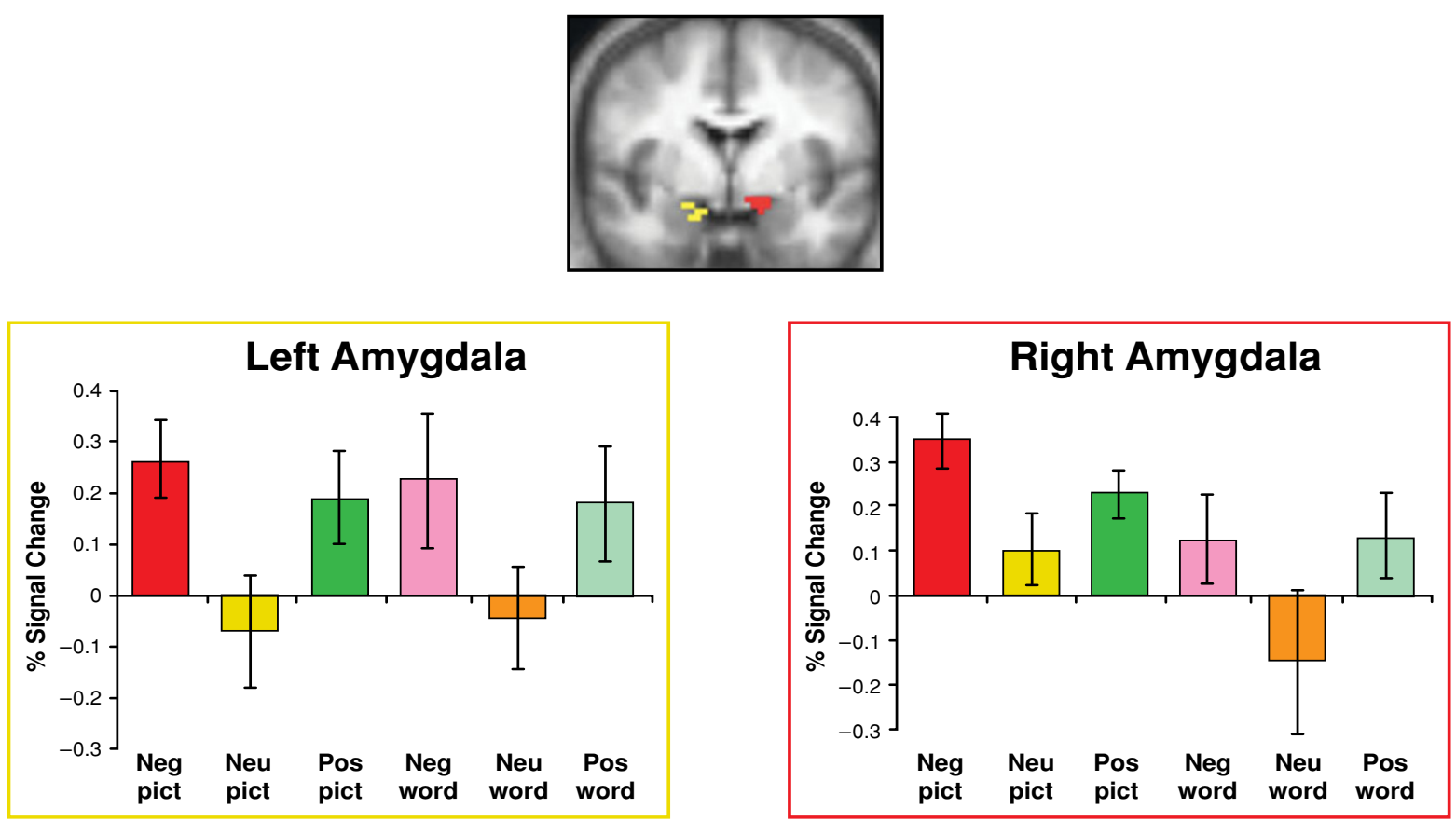

Figure 4. The left amygdala (in yellow) showed an arousal-related response for both pictures and words, whereas the right amygdala (in red) showed an above baseline response only for pictures.

whereas the right amygdala showed an above baseline response only for pictures. This laterality effect was confirmed by a repeated measures ANOVA conducted on the peak signal change in the regions of the right and left amygdala. We considered laterality (left or right), emotion type (positive, negative, or neutral), and stimulus type (picture or word) as within-subjects factors and sex (male or female) as a between-subjects factor. This analysis indicated a main effect of emotion type [positive and negative $>$ neutral; $F(2,18)=4.85, p<.05$; partial $\eta^{2}=$ $.36]$ and an interaction between stimulus type and laterality [the left amygdala responded equally to pictures and words; the right amygdala responded more strongly to pictures; $F(1,19)=4.11, p<.05$; partial $\left.\eta^{2}=.18\right]$. No other factors interacted with laterality, suggesting that in this task design, stimulus type was the predominant characteristic that led to laterality effects in the amygdala.

\section{Valence Responses}

To examine the regions that showed a differential response based on valence, we contrasted activity for high-arousal positive items with activity for high-arousal negative items (and vice versa). Because positive and negative items were matched in arousal, activation differences should be related to differences in valence. We first performed this analysis by collapsing across pictures and words. Within the PFC, the ventrolateral PFC responded more strongly to negative items than to positive items (red regions of Figure 5; Talairach coordinates $-45,15,16$ [BA 44] and 35, 6, 25 [BA $44 / 6]$ ), whereas a region of the medial PFC (Figure 5, in green) responded more to positive items than to negative items (Talairach coordinates -9, 27, 10 [BA 24/32/8 5]). In addition to these distinctions within the PFC, positive stimuli elicited greater activity than did negative stimuli in a large region spanning the precuneus and inferior parietal lobe, in the right superior temporal gyrus, in the inferior/ middle temporal gyrus bilaterally, and in the fusiform/lingual gyrus bilaterally (Figure 5; Table 5).

When valence effects were examined for pictures, the same general patterns of activity were revealed in the PFC (Figure 6, panel A): The bilateral ventrolateral PFC responded differentially to negative pictures, in comparison with positive pictures (BA 44/45/47), whereas activity in the medial PFC (BA 10) showed a preferential response to positive pictures, in comparison with negative pictures. Valence effects also were revealed outside of the PFC (see Tables 4 and 5). Activity was greater during processing of negative pictures than during processing of positive pictures in the superior temporal gyrus bilaterally, the left middle temporal gyrus, and the left anterior temporal lobe. The converse effect (processing of positive $>$ negative) held in all of the regions described above for all the stimuli and was additionally revealed in the left lingual gyrus, the right cuneus, and a region spanning the left postcentral and precentral gyri.

When valence effects were examined for verbal stimuli, the effects were much less extensive than had been noted with pictures (Figure 6, panel B). Within the PFC, only a single left lateral PFC region (BA 44) showed greater activity for negative words than for positive words, and no 

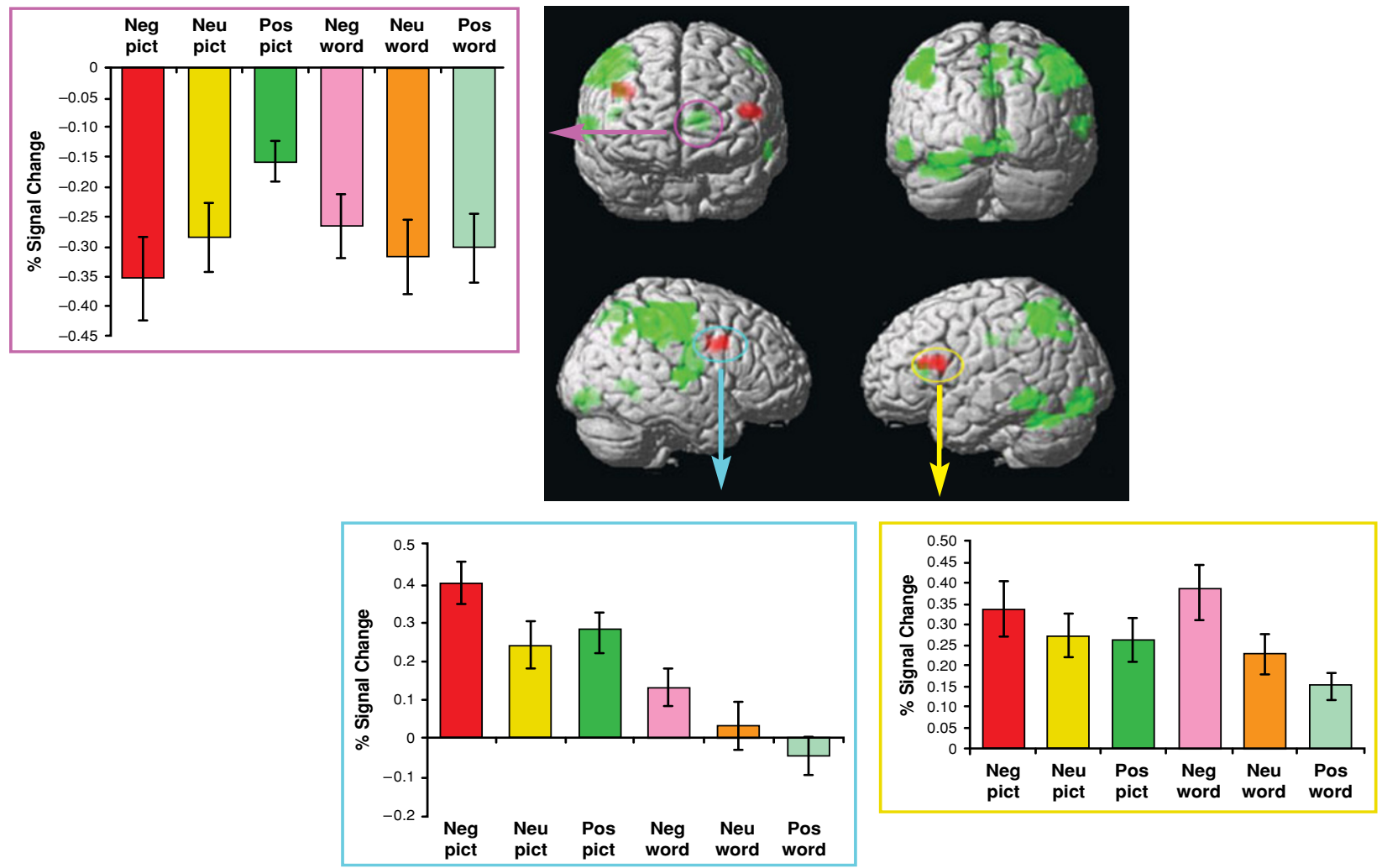

Figure 5. Valence responses, collapsing across pictures and words. The lateral prefrontal cortex (PFC; in red) responded more to negative than to neutral items, whereas the medial PFC, precuneus/inferior parietal lobe, and superior, middle, and inferior temporal gyri (all in green) responded more to positive items than to negative ones.

PFC regions showed the opposite effect. Beyond the PFC, only four of the regions noted above showed valencerelated responses for the words: Activity in a region spanning the superior temporal gyrus and the inferior parietal lobe showed a greater response to negative words than to positive words, and activity in the left fusiform/lingual gyrus (BAs 18 and 19) and the right middle temporal gyrus (BA 21) showed a greater response to positive words than to negative words.

\section{DISCUSSION}

The present study revealed neural processes modulated by stimulus arousal and by stimulus valence, and identified the arousal- and valence-based processes that did, and did not, overlap for emotional pictures and words. We first will focus on our findings in the amygdala and the PFC, the two regions that have received the most attention in prior investigations of emotional processing. We then will turn our attention to the additional regions identified as responding in an arousal-based or valence-dependent manner.

\section{Amygdala Response to Emotional Stimuli}

With regard to processing in the amygdala, the results confirmed and extended those of prior investiga- tions, demonstrating that the amygdala can respond in a valence-independent manner for both pictures and words. The amygdalar regions revealed in this study were equally active during the processing of positive and negative stimuli, and this activity occurred despite the fact that the participants' task did not require them to focus on their emotional response during the stimulus processing. Thus, the amygdalar response to high-arousal stimuli appears to generalize across a range of stimulus types and experimental tasks. It is important to note that whereas a prior study (Royet et al., 2000) suggested that olfactory stimuli may be more effective than visual stimuli in activating the amygdala, the present results suggest that the processing of visual information can be sufficient to elicit amygdala activity (consistent with many other studies that have shown significant amygdala activity to stimuli, including faces, pictures, and words; reviewed by Baas et al., 2004; Hamann, 2001; Kensinger, in press).

The results did indicate, however, that laterality effects in the amygdala can be related to stimuli characteristics. In particular, whereas the activity in the left amygdala showed a pattern of arousal-based responding that was consistent for both pictures and words, the activity in the right amygdala did not generalize across stimulus type. The right dorsal amygdala showed an above baseline re- 

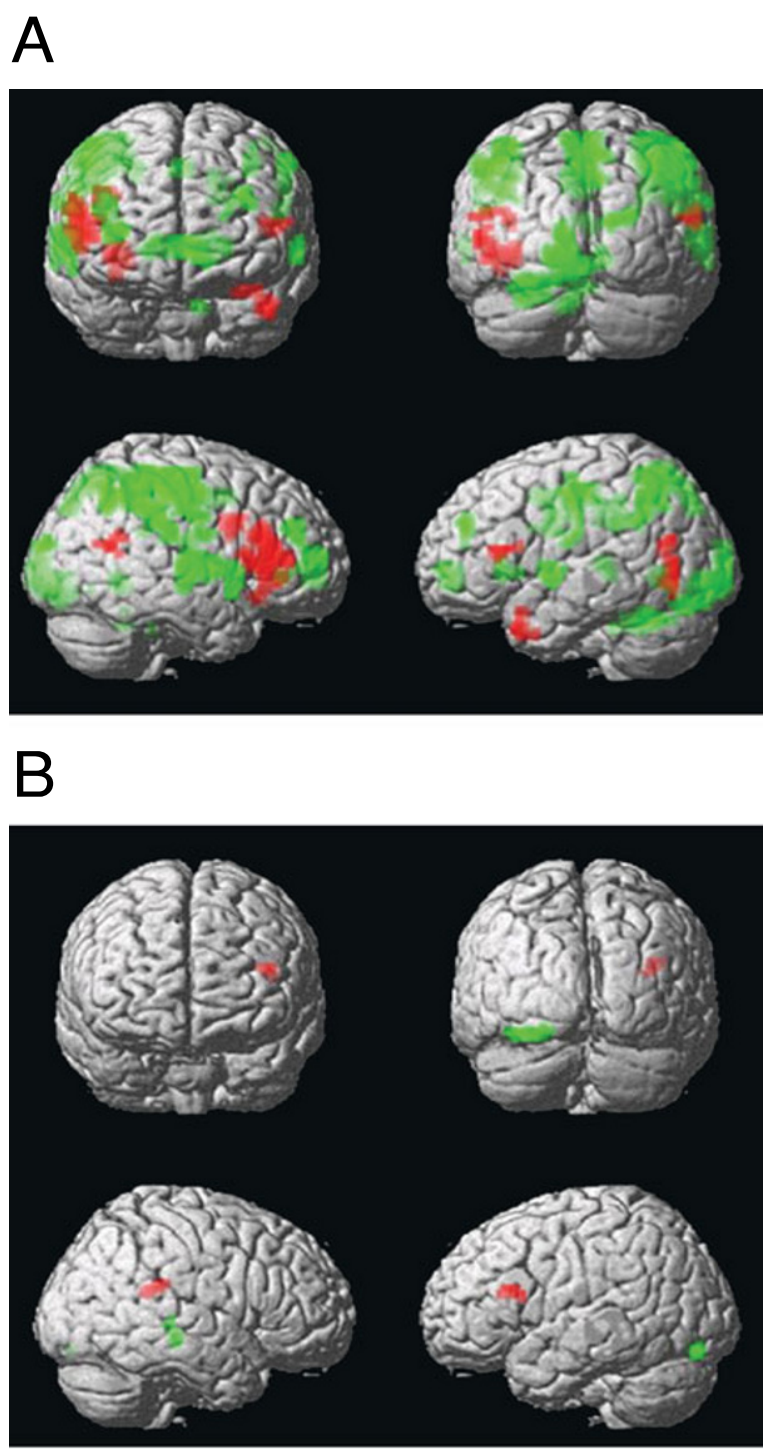

Figure 6. Valence responses for (A) pictures and (B) words. Regions in red showed a disproportionate response to negative stimuli, in comparison with positive stimuli, whereas regions in green showed greater activity for positive items than for negative items. Many of the regions that showed a greater response to positive versus negative pictures (e.g., the medial PFC, the precuneus/ inferior parietal lobe, and the superior temporal gyrus; panel A) did not show a comparable valence response to words (panel B).

sponse only for pictures, and not for words. In fact, stimulus type (picture or word) was the only factor assessed that interacted with laterality of amygdala activity. This lateralization may reflect a true, stimulus-specific effect, as is found throughout much of the medial temporal lobe, with verbal stimuli leading to left-lateralized activation and pictorial stimuli leading to right-lateralized or bilateral activation (and see Markowitsch, 1998). Alternatively, however, the specificity of the right-amygdala response (to pictures and not to words) and the generality of the left-amygdala response (to both stimulus types) may reflect their respective roles in automatic processing (perhaps more likely to occur for pictures than for words) versus elaborative, associative, or conceptual processing (which may occur for both pictures and words; see Glascher \& Adolphs, 2003; Phelps et al., 2001). The latter interpretation would be consistent with recent evidence indicating that left-lateralized amygdala activity tends to be elicited across a wider range of tasks than is right-lateralized amygdala activity (see the meta-analysis by Baas et al., 2004).

It is important to note that the amygdalar regions identified in the present study are located dorsally. It has been proposed previously (see Kim et al., 2003) that the dorsal amygdala may respond in an arousal-based fashion, whereas the ventral amygdala may respond differentially on the basis of valence. Our imaging parameters did not allow a strong signal in the ventral amygdala (a common problem in fMRI studies; see Johnstone et al., 2005), and therefore, the present study could not assess whether there are ventral subregions of the amygdala that respond in a valence-dependent manner. Nevertheless, the results indicate that there are regions of the right and left amygdala that respond in an arousal-based manner, even when participants are not asked to focus on their emotional responses to stimuli.

\section{PFC Response to Emotional Stimuli}

In contrast to the arousal-based amygdala response, a number of PFC regions responded in a valence-dependent manner. The results were generally consistent with those in prior studies demonstrating that lateral $\mathrm{PFC}$ regions respond to aversive stimuli, whereas medial PFC regions respond to positive stimuli (e.g., O’Doherty et al., 2001; Small et al., 2001). In the present study, the ventrolateral PFC responded more to negative stimuli than to positive stimuli, although the effect was more apparent when pictures were processed. ${ }^{5}$ In contrast, a medial PFC region responded more to positive pictures than to negative pictures, although there were no PFC regions that showed a preferential response to positive words, in comparison with negative words.

There also was a suggestion of a ventral/dorsal distinction within the PFC: For the pictorial stimuli, the ventrolateral PFC was active during the processing of negative items, whereas the dorsolateral PFC was active during the processing of positive items. Ventral/dorsal distinctions within the PFC have been noted before (typically, with the left ventrolateral PFC active for negative stimuli and the right dorsolateral PFC active for positive stimuli; see, e.g., Dolcos et al., 2004; Sutton et al., 1997), but the emphasis has typically been placed on the left/right distinction, rather than the ventral/dorsal distinction. Although the present results are only suggestive, future studies may do well to examine whether stimulus valence affects whether PFC activity is located ventrally or dorsally.

Not all of the PFC, however, responded in a valencebased fashion: Both a dorsomedial and a ventromedial PFC region showed comparable responses to positive and 
Table 4

Regions That Showed a Valence-Based Response, With Greater Activity for Negative Items Than for Positive Items

\begin{tabular}{|c|c|c|c|c|c|}
\hline Lobe & Region & Hemisphere & $\begin{array}{c}\text { Talairach } \\
\text { Coordinates of } \\
\text { Peak Voxel } \\
(x, y, z)\end{array}$ & $\begin{array}{c}\text { MNI } \\
\text { Coordinates of } \\
\text { Peak Voxel } \\
(x, y, z)\end{array}$ & $\begin{array}{c}\text { Approximate } \\
\text { Brodmann } \\
\text { Area }\end{array}$ \\
\hline \multicolumn{6}{|c|}{ Negative $>$ Positive (All Items) } \\
\hline Frontal & $\begin{array}{l}\text { Middle frontal gyrus } \\
\text { Inferior frontal gyrus }\end{array}$ & $\begin{array}{l}\mathrm{L} \\
\mathrm{L} \\
\mathrm{R}\end{array}$ & $\begin{array}{l}-51,30,15 \\
-45,15,16 \\
35,6,25\end{array}$ & $\begin{array}{l}-51,30,18 \\
-45,15,18 \\
35,5,27\end{array}$ & $\begin{array}{c}46 \\
44 \\
44 / 6\end{array}$ \\
\hline \multicolumn{6}{|c|}{ Negative $>$ Positive (Pictures) } \\
\hline Frontal & Inferior/middle frontal gyrus & $\mathrm{L}$ & $\begin{array}{l}-44,30,12 \\
-42,15,13\end{array}$ & $\begin{array}{l}-45,15,18 \\
-42,15,15\end{array}$ & $\begin{array}{l}45 \\
44\end{array}$ \\
\hline & & $\mathrm{R}$ & $\begin{array}{l}56,24,21 \\
56,23,2\end{array}$ & $\begin{array}{l}56,23,24 \\
56,24,3\end{array}$ & $\begin{array}{c}45,9,46 \\
47\end{array}$ \\
\hline & & & $36,20,-13$ & $36,21,-14$ & 47 \\
\hline Temporal & Superior temporal & $\mathrm{L}$ & $\begin{array}{l}-56,-60,29 \\
-44,13,-25\end{array}$ & $\begin{array}{l}-56,-63,28 \\
-44,15-29\end{array}$ & $\begin{array}{l}39 \\
38\end{array}$ \\
\hline & & $\mathrm{R}$ & $60,-51,22$ & $61,-53,21$ & $22 / 39$ \\
\hline & Middle temporal gyrus & $\mathrm{L}$ & $-50,-67,9$ & $-51,-69,6$ & 37 \\
\hline \multicolumn{6}{|c|}{ Negative $>$ Positive (Words) } \\
\hline Frontal & Inferior frontal gyrus & $\mathrm{L}$ & $-45,15,16$ & $-45,15,18$ & 44 \\
\hline Temporal & Superior temporal gyrus & $\mathrm{R}$ & $33,-43,19$ & $33,-45,18$ & 22 \\
\hline Parietal & Inferior parietal & $\mathrm{R}$ & $39,-34,24$ & $39,-36,24$ & 40 \\
\hline
\end{tabular}

negative stimuli, and these arousal-based responses occurred for both pictures and words. As was discussed in the introduction, there has been tremendous ambiguity with regard to the role of the medial PFC in emotional processing. Much of this ambiguity likely results from the fact that the medial PFC is a large region that does not respond in a homogenous fashion. The results of the present study bolster this claim, revealing three distinct regions of the medial PFC (Figure 7). Two of these regions (the most dorsal and ventral of the regions; in blue) responded in an arousal-based fashion, whereas the third region (in green) showed a valence-based, preferential response to positive pictures versus negative pictures. These distinctions within the medial PFC emerged when all the stimuli were analyzed (Figure 7A), as well as when only responses to pictures were considered (Figure 7B).

The pattern of activity in the two most dorsal medial PFC regions paralleled that described by Dolcos et al. (2004): They too found that the most dorsal region showed an arousal-based response, whereas the more inferior region responded preferentially to positive stimuli. The replication of this distinction in the present study is noteworthy, given the very different tasks used in the two experiments (rating of pleasantness in the study by Dolcos and colleagues vs. rating of animacy and commonality in the present experiment). Thus, these medial PFC responses appear to generalize across a range of tasks. The study by Dolcos and colleagues did not, however, identify the most ventral region revealed in the present study. It is possible that the difficulty in imaging this ventral region prevented its arousal-based response from being identified previously, although another alternative worth further exploration is that this ventral region may play a larger role when tasks do not require explicit evaluation of emotional responses (see Anders et al., 2004).

\section{Other Arousal-Based and Valence-Dependent Responses}

In addition to clarifying the pattern of response in the amygdala and PFC, the present study identified other regions that responded in an arousal-based versus a valence-dependent manner. Of particular interest, arousal responses were noted in the anterior temporal lobe bilaterally and in a region spanning the temporo-occipital junction. Prior studies have noted that activity in these regions is modulated by the emotional relevance of stimuli (e.g., Dolan, Lane, Chua, \& Fletcher, 2000; Lane, Fink, et al., 1997; Lane, Reiman, et al., 1997; Tabert et al., 2001; Taylor et al., 1998), but it has been unclear whether the responses were valence dependent or independent (see Mourao-Miranda et al., 2003, for evidence that visual processing can vary with both dimensions) and whether the responses would exist when participants were not required to emotionally evaluate the stimuli. In fact, it had been proposed that the anterior temporal lobe plays a principal role in eliciting a subjective emotional experience (Mesulam, 1985) and would not be active on tasks that do not demand monitoring or labeling of an affective response (Lane, Fink, et al., 1997; Lane, Reiman, et al., 1997). In contrast to this proposal, the present results suggest that these temporal and occipital regions show arousal-based responses for both pictures and words, even when emotional monitoring is not required.

Outside of the PFC, the only valence effects that occurred for both pictures and words were in the lingual/fusiform gyrus (positive $>$ negative) and in the superior temporal 
Table 5

Regions That Showed a Valence-Based Response, With Greater Activity for Positive Items Than for Negative Items

\begin{tabular}{|c|c|c|c|c|c|}
\hline Lobe & Region & Hemisphere & $\begin{array}{c}\text { Talairach } \\
\text { Coordinates of } \\
\text { Peak Voxel } \\
(x, y, z)\end{array}$ & $\begin{array}{c}\text { MNI } \\
\text { Coordinates of } \\
\text { Peak Voxel } \\
(x, y, z)\end{array}$ & $\begin{array}{c}\text { Approximate } \\
\text { Brodmann } \\
\text { Area }\end{array}$ \\
\hline \multicolumn{6}{|c|}{ Positive $>$ Negative (All) } \\
\hline \multirow[t]{2}{*}{ Frontal } & Precentral gyrus & $\mathrm{R}$ & $48,-12,53$ & $48,-15,57$ & 4 \\
\hline & Superior frontal/anterior cingulate gyrus & $\mathrm{L}$ & $-9,27,10$ & $-9,27,12$ & $24,32,8$ \\
\hline \multirow[t]{3}{*}{ Temporal } & Superior temporal gyrus & $\mathrm{R}$ & $60,-20,6$ & $60,-21,5$ & 22 \\
\hline & Middle temporal gyrus & $\mathrm{L}$ & $56,-44,-5$ & $56,-45,-9$ & 21 \\
\hline & Inferior temporal gyrus & $\mathrm{L}$ & $-56,-56,-5$ & $-56,-57,-9$ & 37 \\
\hline \multirow[t]{6}{*}{ Parietal } & Postcentral gyrus & $\mathrm{R}$ & $50,-18,40$ & $51,-21,42$ & 3 \\
\hline & Precuneus & $\mathrm{L}$ & $44,-71,37$ & $-44,-75,36$ & 39 \\
\hline & & Bilateral & $-3,-36,43$ & $-3,-39,45$ & 7 \\
\hline & Posterior cingulate gyrus & $\mathrm{L}$ & $-3,-34,32$ & $-3,-37,33$ & 31 \\
\hline & Inferior parietal lobe & $\mathrm{L}$ & $-47,-53,44$ & $-47,-57,45$ & 40 \\
\hline & & $\mathrm{R}$ & $45,-42,41$ & $45,-45,42$ & 40 \\
\hline \multirow[t]{2}{*}{ Occipital } & Lingual/fusiform gyrus & $\mathrm{L}$ & $-27,-76,-9$ & $-27,-78,-15$ & 18,19 \\
\hline & & $\mathrm{R}$ & $8,-82,-3$ & $8,-84,-8$ & 18 \\
\hline \multirow[t]{2}{*}{ Cerebellum } & & $\mathrm{L}$ & $-30,-60,-20$ & $-30,-61,-27$ & \\
\hline & Positive $=$ & Negative $(\mathrm{Pi}$ & tures) & & \\
\hline \multirow[t]{6}{*}{ Frontal } & Middle frontal gyrus & $\mathrm{L}$ & $-30,45,25$ & $-30,45,30$ & 10 \\
\hline & & $\mathrm{R}$ & $38,41,23$ & $38,41,27$ & 10 \\
\hline & Precentral gyrus & $\mathrm{L}$ & $-32,-24,48$ & $-32,-27,51$ & 4 \\
\hline & & $\mathrm{R}$ & $39,-23,56$ & $39,-27,60$ & 4 \\
\hline & Medial frontal gyrus & Bilateral & $-6,52,-3$ & $-6,54,-1$ & 10 \\
\hline & & & $17,32,2$ & $17,33,4$ & $9 / 24 / 32$ \\
\hline \multirow[t]{3}{*}{ Temporal } & Superior temporal gyrus & $\mathrm{L}$ & $-60,-3,-2$ & $-61,-3,-3$ & 22 \\
\hline & & $\mathrm{R}$ & $60,0,5$ & $61,0,5$ & 22 \\
\hline & Fusiform gyrus & $\mathrm{L}$ & $-30,-80,-11$ & $-30,-82,-18$ & \\
\hline \multirow[t]{7}{*}{ Parietal } & Inferior parietal lobe & $\mathrm{L}$ & $-38,-53,55$ & $-38,-57,57$ & 40 \\
\hline & & $\mathrm{R}$ & $45,-31,30$ & $45,-33,31$ & 40 \\
\hline & Postcentral gyrus & $\mathrm{L}$ & $-54,-16,31$ & $-55,-18,33$ & 3 \\
\hline & & $\mathrm{R}$ & $35,-24,45$ & $35,-27,48$ & 3 \\
\hline & Precuneus & Bilateral & $3,-67,53$ & $3,-72,54$ & 7 \\
\hline & Cingulate gyrus & Bilateral & $-3,-15,37$ & $-3,-17,39$ & 24 \\
\hline & & & $-3,-31,35$ & $-3,-34,36$ & 31 \\
\hline \multirow[t]{3}{*}{ Occipital } & Cuneus & $\mathrm{R}$ & $24,-90,21$ & $24,-94,18$ & 18,19 \\
\hline & Lingual gyrus & $\mathrm{L}$ & $-6,-96,3$ & $-6,-99,-2$ & 18 \\
\hline & & $\mathrm{L}$ & $-3,-87,-5$ & $-3,-89,-11$ & 18 \\
\hline \multirow[t]{2}{*}{ Cerebellum } & Cerebellum & $\mathrm{L}$ & $-30,-53,-18$ & $-30,-54,-25$ & \\
\hline & Putamen & $\mathrm{L}$ & $-21,20,-1$ & $-21,20,0$ & \\
\hline & Positive & $>$ Negative $(\mathrm{W}$ & ords) & & \\
\hline \multirow[t]{3}{*}{ Temporal } & Fusiform/lingual gyrus & $\mathrm{L}$ & $-24,-80,-9$ & $-24,-82,-15$ & 18 \\
\hline & & & $-35,-80,-11$ & $-35,-82,-18$ & 19 \\
\hline & Middle temporal gyrus & $\mathrm{R}$ & $43,-26,-3$ & $43,-26,-5$ & 21 \\
\hline
\end{tabular}

gyrus (negative $>$ positive). There were no suggestions of laterality effects in the non-PFC regions (i.e., no evidence to support the hypothesis that left-lateralized activity is greater for positive than for negative stimuli and right-lateralized activity is greater for negative than for positive stimuli). It may be that these valence-based effects are more likely to occur when participants' tasks require the explicit monitoring, labeling, or expression of emotion.

\section{Conclusions}

In conclusion, the present results suggest that arousalrelated responses occur in the amygdala, dorsomedial PFC, ventromedial PFC, anterior temporal lobe, and temporooccipital junction. These arousal-based responses occurred for both pictures and words, with stimulus type primarily affecting the laterality of activity: Throughout the temporal lobe (and including the amygdala), activity was bilateral or right-lateralized for pictures and leftlateralized for words. These arousal-based responses were relatively consistent with those observed in prior studies requiring participants to label or monitor their affective response, suggesting that these effects may generalize not only across stimulus type, but also across different experimental tasks. Valence-dependent responses were best characterized by a lateral PFC versus medial PFC distinction (for processing of negative and positive stimuli, respectively), although the valence effects were much stronger for pictures than for words. Future studies will be required to clarify whether valence effects are always less consistent for verbal than for nonverbal stimuli or whether 

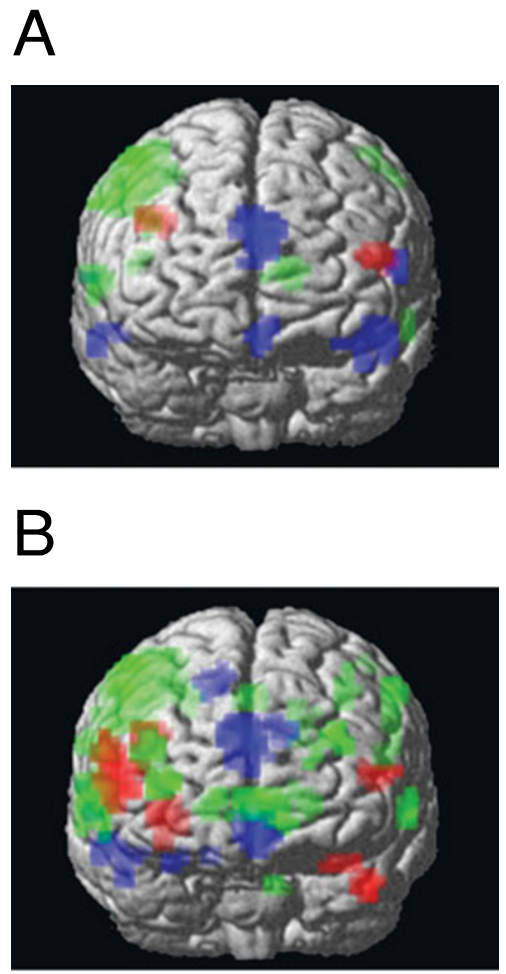

Figure 7. Three regions of the medial prefrontal cortex (PFC) were identified: Two were related to arousal (in blue), whereas one was related to positive valence (in green). The same pattern of response was revealed in these medial PFC regions (A) when all the items were analyzed or (B) when only pictures were analyzed. Red, negative $>$ positive; green, positive $>$ negative; blue, negative $>$ neutral and positive $>$ neutral.

valence-dependent processing of verbal stimuli is more likely to occur when the participants' task requires monitoring or labeling of an affective response.

\section{REFERENCES}

Adolphs, R., Tranel, D., Damasio, H., \& Damasio, A. R. (1995). Fear and the human amygdala. Journal of Neuroscience, 15, 5879-5891.

Aftanas, L. I., Varlamov, A. A., Pavlov, S. V., Makhnev, V. P., \& Reva, N. V. (2001). Affective picture processing: Event-related synchronization within individually defined human theta band is modulated by valence dimension. Neuroscience Letters, 303, 115-118.

Anders, S., Lotze, M., Erb, M., Grodd, W., \& Girbaumer, N. (2004). Brain activity underlying emotional valence and arousal: A responserelated fMRI study. Human Brain Mapping, 23, 200-209.

Anderson, A. K., Christoff, K., Stappen, I., Panitz, D., GhahreMANI, D. G., Glover, G., ET AL. (2003). Dissociated neural representations of intensity and valence in human olfaction. Nature Neuroscience, 6, 196-202.

BaAs, D., Aleman, A., \& Kahn, R. S. (2004). Lateralization of amygdala activation: A systematic review of functional neuroimaging studies. Brain Research Reviews, 45, 96-103.

Bowers, D., Bauer, R. M., Coslett, H. B., \& Heilman, K. M. (1985). Processing of face by patients with unilateral hemisphere lesions: Dissociations between judgments of facial affect and facial identity. Brain \& Cognition, 4, 258-272.

Bradley, M. M., \& Lang, P. J. (1999). Affective norms for English words [CD-ROM]. Gainesville: University of Florida, NIMH Center for the Study of Emotion and Attention.

Breiter, H. C., Etcoff, N. L., Whalen, P. J., Kennedy, W. A., Rauch, S. L., BUCKNER, R. L., ET AL. (1996). Response and habituation of the human amygdala during visual processing of facial expression. Neuron, 17, 875-887.

Broks, P., Young, A. W., Maratos, E. J., Coffey, P. J., Calder, A. J., IsAAC, C. L., ET AL. (1998). Face processing impairments after encephalitis: Amygdala damage and recognition of fear. Neuropsychologia, 36, 59-70.

CAHILl, L. (2003). Sex- and hemisphere-related influences on the neurobiology of emotionally influenced memory. Progress in NeuroPsychopharmacology \& Biological Psychiatry, 27, 1235-1241.

Canli, T., Desmond, J. E., Zhao, Z., Glover, G., \& Gabrieli, J. D. E. (1998). Hemispheric asymmetry for emotional stimuli detected with fMRI. NeuroReport, 9, 3233-3239.

Collins, D. L., Zijdenbos, A. P., Kollokian, V., Sled, J. G., Kabani, N. J., Holmes, C. J., \& Evans, A. C. (1998). Design and construction of a realistic digital brain phantom. IEEE Transactions on Medical Imaging, 17, 463-468.

Coltheart, M. (1981). The MRC psycholinguistic database. Quarterly Journal of Experimental Psychology, 33A, 497-505.

Cunningham, W. A., Raye, C. L., \& Johnson, M. K. (2004). Implicit and explicit evaluation: fMRI correlates of valence, emotional intensity, and control in the processing of attitudes. Journal of Cognitive Neuroscience, 16, 1717-1729.

Dale, A. M. (1999). Optimal experimental design for event-related fMRI. Human Brain Mapping, 8, 109-114.

DAVIDSON, R. J. (1995). Cerebral asymmetry, emotion, and affective style. In R. J. Davidson \& K. Hugdahl (Eds.), Brain asymmetry (pp. 361-387). Cambridge, MA: MIT Press.

DAVIDSON, R. J., \& IRWIN, W. (1999). The functional neuroanatomy of emotion and affective style. Trends in Cognitive Sciences, 3, 11-20.

Dolan, R. J., Lane, L., Chua, P., \& Fletcher, P. (2000). Dissociable temporal lobe activations during emotional episodic memory retrieval. NeuroImage, 11, 203-209.

Dolcos, F., LABAR, K. S., \& CABEZA, R. (2004). Dissociable effects of arousal and valence on prefrontal activity indexing emotional evaluation and subsequent memory: An event-related fMRI study. NeuroImage, 23, 64-74.

FisHER, R. A. (1950). Statistical methods for research workers. London: Oliver \& Boyd.

Garavan, H., Pendergrass, J. C., Ross, T. J., Stein, E. A., \& RisINGER, R. C. (2001). Amygdala response to both positively and negatively valenced stimuli. NeuroReport, 12, 2779-2783.

George, M. S., Ketter, T. A., \& Post, R. M. (1993). SPECT and PET imaging in mood disorders. Journal of Clinical Psychiatry, 54, 6-13.

GlasCHER, J., \& ADOLPHS, R. (2003). Processing of the arousal of subliminal and supraliminal emotional stimuli by the human amygdala. Journal of Neuroscience, 23, 2779-2783.

Hamann, S. [B.] (2001). Cognitive and neural mechanisms of emotional memory. Trends in Cognitive Sciences, 5, 394-400.

Hamann, S. B., Ely, T. D., Grafton, S. T., \& Kilts, C. D. (1999). Amygdala activity related to enhanced memory for pleasant and aversive stimuli. Nature Neuroscience, 2, 289-293.

Hamann, S. B., Ely, T. D., Hoffman, J. M., \& Kilts, C. D. (2002). Ecstasy and agony: Activation of the human amygdala in positive and negative emotion. Psychological Science, 13, 135-141.

Hamann, S. [B.], \& MaO, H. (2002). Positive and negative emotional verbal stimuli elicit activity in the left amygdala. NeuroReport, 13, 15-19.

Hariri, A. R., Bookheimer, S. Y., \& MaZziotta, J. C. (2000). Modulating emotional responses: Effects of a neocortical network on the limbic system. NeuroReport, 11, 43-48.

HARRINGTON, A. (1995). Unfinished business: Models of laterality in the nineteenth century. In R. J. Davidson \& K. Hugdahl (Eds.), Brain asymmetry (pp. 3-27). Cambridge, MA: MIT Press.

Hellige, J. B. (1993). Hemispheric asymmetry. Cambridge, MA: Harvard University Press.

Hutcherson, C. A., Goldin, P. R., Ochsner, K. N., Gabrieli, J. D. [E.], Barrett, L. F., \& Gross, J. J. (2005). Attention and emotion: Does 
rating emotion alter neural responses to amusing and sad films? NeuroImage, 27, 656-668.

Irwin, W., Davidson, R. J., Lowe, M. J., Mock, B. J., Sorenson, J. A., \& TURSKI, P. A. (1996). Human amygdala activation detected with echo-planar functional magnetic resonance imaging. NeuroReport, 7, 1765-1769.

Johnstone, T., Somerville, L. H., Alexander, A. L., Oakes, T. R., Davidson, R. J., Kalin, N. H., \& Whalen, P. J. (2005). Stability of amygdala BOLD response to fearful faces over multiple scan sessions. NeuroImage, 25, 1112-1123.

KENSINGER, E. A. (in press). Neuroimaging the formation and retrieval of emotional memories. In Brain mapping: New research. Hauppauge, NY: Nova Science.

Kim, H., Somerville, L. H., Johnstone, T., Alexander, A. L., \& Whalen, P. J. (2003). Inverse amygdala and medial prefrontal cortex responses to surprised faces. NeuroReport, 14, 2317-2322.

Lane, R. D., Fink, G. R., Chau, P. M.-L., \& Dolan, R. J. (1997). Neural activation during selective attention to subjective emotional responses. NeuroReport, 8, 3969-3972.

Lane, R. D., Reiman, E. M., Bradley, M. M., Lang, P. J., Ahern, G. L., Davidson, R. J., \& Schwartz, G. E. (1997). Neuroanatomical correlates of pleasant and unpleasant emotion. Neuropsychologia, 35, 1437-1444.

LANG, P. J., Bradley, M. M., \& CUthbert, B. N. (1997). International affective picture system (IAPS): Technical manual and affective ratings. Gainesville: University of Florida, Center for Research in Psychophysiology.

Lang, P. J., Greenwald, M. K., Bradley, M. M., \& Hamm, A. O. (1993). Looking at pictures: Affective, facial, visceral and behavioral reactions. Psychophysiology, 30, 261-273.

Lange, K., Williams, L. M., Young, A. W., Bullmore, E. T., BramMER, M. J., Williams, S. C., ET AL. (2003). Task instructions modulate neural responses to fearful facial expressions. Biological Psychiatry, 53, 226-232.

Lazar, N. A., Luna, B., Sweeney, J. A., \& Eddy, W. F. (2002). Combining brains: A survey of methods for statistical pooling of information. NeuroImage, 16, 538-550.

Lee, G. P., Loring, D. W., Meader, K. J., \& Brooks, B. B. (1990). Hemispheric specialization for emotional expression: A reexamination of results from intracarotid administration of sodium amobarbital. Brain \& Cognition, 12, 267-280.

Markowitsch, H. J. (1998). Differential contribution of right and left amygdala to affective information processing. Behavioural Neurology, 11, 233-244.

Mehrabian, A., \& Russell, J. A. (1974). An approach to environmental psychology. Cambridge, MA: MIT Press.

Mesulam, M.-M. (1985). Patterns in behavioral neuroanatomy: Association areas, the limbic system, and hemispheric specialization. In M.-M. Mesulam (Ed.), Principles of behavioral neurology (pp. 1-70). Philadelphia: Davis.

Morris, J. S., Frith, C. D., Perrett, D. I., Rowland, D., Young, A. W., Calder, A. J., \& Dolan, R. J. (1996). A differential neural response in the human amygdala to fearful and happy facial expressions. Nature, 383, 812-815.

Mourao-Miranda, J., Volchan, E., Moll, J., de Oliveira-Souza, R., Oliveira, L., Bramati, I., ET AL. (2003). Contributions of stimulus valence and arousal to visual activation during emotional perception. NeuroImage, 20, 1955-1963.

O’Doherty, J., Critchley, H., Deichmann, R., \& Dolan, R. J. (2003). Dissociating valence of outcome from behavioral control in human orbital and ventral prefrontal cortices. Journal of Neuroscience, 23, 7931-7939.

O’Doherty, J., Kringelbach, M. L., Rolls, E. T., Hornak, J., \& ANDREws, C. (2001). Abstract reward and punishment representations in the human orbitofrontal cortex. Nature Neuroscience, 4, 95102.

O’Doherty, J., Rolls, E. T., Francis, S., Bowtell, R., McGlone, F., Kobal, G., ET AL. (2000). Sensory-specific satiety-related olfactory activation of the human orbitofrontal cortex. NeuroReport, 11, 893897.
Oliva, A., Mack, M. L., Shrestha, M., \& Peeper, A. (2004, August). Identifying the perceptual dimensions of visual complexity of scenes. Paper presented at the 26th Annual Meeting of the Cognitive Science Society, Chicago.

Paradiso, S., Chemerinski, E., Yazici, K. M., Tartaro, A., \& RobINSON, R. G. (1999). Frontal lobe syndrome reassessed: Comparison of patients with lateral or medial frontal brain damage. Journal of Neurology, Neurosurgery, \& Psychiatry, 67, 664-667.

Paradiso, S., Johnson, D. L., Andreasen, N. C., O’Leary, D. S., Watkins, G. L., Ponto, L. L., \& Hichwa, R. D. (1999). Cerebral blood flow changes associated with attribution of emotional valence to pleasant, unpleasant, and neutral visual stimuli in a PET study of normal subjects. American Journal of Psychiatry, 156, 1618-1629.

Phelps, E. A., O'Connor, K. J., Gatenby, J. C., Gore, J. C., Grillon, C., \& DAVIS, M. (2001). Activation of the left amygdala to a cognitive representation of fear. Nature Neuroscience, 4, 437-441.

Phillips, M. L., Young, A. W., Senior, C., Brammer, M., Andrew, C., CAlder, A. J., ET AL. (1997). A specific neural substrate for perceiving facial expressions of disgust. Nature, 389, 495-498.

Royet, J.-P., Zald, D., Versace, R., Costes, N., Lavenne, F., Koenig, O., \& Gervais, R. (2000). Emotional responses to pleasant and unpleasant olfactory, visual, and auditory stimuli: A positron emission tomography study. Journal of Neuroscience, 20, 7752-7758.

Russell, J. (1980). A circumplex model of affect. Journal of Personality \& Social Psychology, 39, 1161-1178.

Schneider, F., Gur, R. E., Mozley, L. H., Smith, R. J., Mozley, P. D., Censits, D. M., ET AL. (1995). Mood effects on limbic blood flow correlate with emotional self-rating: A PET study with oxygen-15 labeled water. Psychiatry Research, 61, 265-283.

Scott, S. K., Young, A. W., Calder, A. J., Hellawell, D. J., AggleTON, J. P., \& JoHnSON, M. (1997). Impaired auditory recognition of fear and anger following bilateral amygdala lesions. Nature, $\mathbf{3 8 5}, 254-$ 257.

Slotnick, S. D., Moo, L. R., Segal, J. B., \& Hart, J., JR. (2003). Distinct prefrontal cortex activity associated with item memory and source memory for visual shapes. Cognitive Brain Research, 17, 7582 .

Small, D. M., Gregory, M. D., Mak, Y. E., Gitelman, D., Mesulam, M.-M., \& PARRISH, T. (2003). Dissociation of neural representation of intensity and affective valuation in human gustation. Neuron, 39, 701-711.

Small, D. M., Zatorre, R. J., Dagher, A., Evans, A. C., \& JonesGotman, M. (2001). Changes in brain activity related to eating chocolate: From pleasure to aversion. Brain, 124, 1720-1733.

Starkstein, S. E., Robinson, R. G., Honig, M. A., Parikh, R. M., Joselyn, J., \& Price, T. R. (1989). Mood changes after righthemisphere lesions. British Journal of Psychiatry, 155, 79-85.

Sutton, S. K., Ward, R. T., Larson, C. L., Holden, J. E., Perlman, S. B., \& DAvidson, R. J. (1997). Asymmetry in prefrontal glucose metabolism during appetitive and aversive emotional states: An FDGPET study. Psychophysiology, 34(Suppl.), S89.

Tabert, M. H., Borod, J. C., Tang, C. Y., Lange, G., Wei, T. C., JOHNSON, R., ET AL. (2001). Differential amygdala activation during emotional decision and recognition memory tasks using unpleasant words: An fMRI study. Neuropsychologia, 39, 556-573.

TAlairach, J., \& Tournoux, P. (1988). Co-planar stereotaxic atlas of the human brain: 3-dimensional proportional system: An approach to cerebral imaging (M. Rayport, Trans.). New York: Thieme.

TAYLOR, S. F., LiberZon, I., Fig, L. M., DeCKer, L. R., Minoshima, S., \& KoepPe, R. A. (1998). The effect of emotional content on visual recognition memory: A PET activation study. NeuroImage, 8, 188-197.

Taylor, S. F., Phan, K. L., Decker, L. R., \& Liberzon, I. (2003). Subjective rating of emotionally salient stimuli modulates neural activity. NeuroImage, 18, 650-659.

Teasdale, J. D., Howard, R. J., Cox, S. G., Ha, Y., Brammer, M. J., Williams, S. C., \& Checkley, S. A. (1999). Functional MRI study of the cognitive generation of affect. American Journal of Psychiatry, 156, 209-215.

Tomarken, A. J., Davidson, R. J., Wheeler, R. E., \& Doss, R. C. (1992). Individual differences in anterior brain asymmetry and fun- 
damental dimensions of emotion. Journal of Personality \& Social Psychology, 62, 676-687.

Whalen, P. J., Rauch, S. L., Etcoff, N. L., McInerney, S. C., Lee, M. B., \& JeNIKE, M. A. (1998). Masked presentations of emotional facial expressions modulate amygdala activity without explicit knowledge. Journal of Neuroscience, 18, 411-418.

Whalen, P. J., Shin, L. M., McInerney, S. C., Fischer, H., Wright, C. I., \& RAUCH, S. L. (2001). A functional MRI study of human amygdala responses to facial expressions of fear versus anger. Emotion, 1, 70-83.

Wheeler, R. E., Davidson, R. J., \& Tomarken, A. J. (1993). Frontal brain asymmetry and emotional reactivity: A biological substrate of affective style. Psychophysiology, 30, 82-89.

\section{NOTES}

1. Outside of the scanner, the participants performed a recognition memory task in which they were shown 360 pictures and 360 words and, for each item, were asked to indicate whether they had rated the item for its animacy or for its commonness or had not studied the item. These subsequent-memory data will be reported in a separate publication.

2 . This more lenient threshold was used because conjunction analyses are conservative: They use a strict statistical threshold to test whether identical voxels are activated in two contrasts.
3. Note that because these individual contrasts were conducted with a larger required voxel extent (19 voxels) than were the conjunction analyses (10 voxels), some regions identified by the conjunction analysis were not identified in these individual contrast analyses.

4. Because the amygdala is a relatively small structure, we used both a $3-\mathrm{mm}$ sphere and the more standard $8-\mathrm{mm}$ sphere. The results did not differ qualitatively in these instances, and so here we report the results of the analysis using the more standard $8-\mathrm{mm}$ spherical ROI

5. It is not clear why the valence effects would be more pronounced with pictures than with words; the stimuli were selected so that words and pictures were equally extreme in valence (according to the normative ratings), and the participants did not rate pictures and words in a systematically different fashion with regard to valence. However, any number of properties differ between pictorial and verbal emotional stimuli (e.g., complexity of the stimuli and elicitation of emotion via visual vs. semantic processing) and may explain the differences in valence-based processing for pictures and words. Regardless of the mechanism, the present results suggest that for researchers interested in teasing apart valence effects, it would be prudent to use pictorial stimuli, rather than verbal stimuli.

(Manuscript received July 12, 2005;

revision accepted for publication January 6,2006 .) 